\title{
ECUADOR: ...HASTA QUE SE FUERON TODOS
}

\author{
Ecuador: ...Until There Were None
}

\author{
JUAN CARLOS MACHADO PUERTAS ${ }^{1}$ \\ Universidad de Sussex
}

\begin{abstract}
RESUMEN
El 2007 fue un año de cambios radicales en la política ecuatoriana. Se destaca la batalla política y electoral entre un Ejecutivo encabezado por un líder antisistema y radical, y la desprestigiada clase política que a la postre resultaría en la desaparición del precario sistema de partidos. En este proceso el presidente logró pasar de una situación minoritaria extrema, al no tener ningún respaldo legislativo propio en el Congreso, al extremo opuesto de controlar totalmente una Asamblea Constituyente de plenos poderes. Mientras una muy desilusionada y resentida ciudadanía todavía aplaude la derrota de una clase política corrupta, los problemas estructurales del sistema se han agravado. De manera paradójica, la preocupación actual no se centra ya en la crónica inestabilidad política, sino en la supervivencia misma de la disfuncional democracia ecuatoriana.
\end{abstract}

Palabras clave: Ecuador, 2007, presidente Rafael Correa, democracia, Asamblea Constituyente.

\begin{abstract}
This article highlights the year 2007 as a watershed in Ecuadorian politics. It underscores the fierce political and electoral battle between the radical and anti-systemic President and the established political class which led to the collapse of the nation's precarious party system. Within this process the President maneuvered from an extreme minority position, lacking partisan support in Congress, to one of unfettered control of a fully empowered Constituent Assembly. Whilst disaffected citizens still applaud the defeat of a highly corrupt political class, the country's structural problems have grown even deeper. Paradoxically enough, the current problem is not the country's cronic instability, , rather the very survival of Ecuador's dysfunctional democracy.
\end{abstract}

Key words: Ecuador, 2007, president Rafael Correa, democracy, Constituent Assembly.

\section{TEMAS SALIENTES EN LA REALIDAD NACIONAL Y SU IMPACTO POLÍTICO}

\section{Coyuntura social}

La coyuntura social en el Ecuador podría ser descrita como de tensa calma en un contexto de profunda polarización. Paradójicamente, pese a la campal batalla que libraba el gobierno contra la partidocracia en la arena política, o precisamente a causa de ello, se trató de

1 Agradezco la colaboración de Galo Abril Ojeda (PhD), analista económico, para la elaboración de la sección sobre coyuntura económica. 
un año de una inusual calma en lo social. ${ }^{2}$ Cuatro son los factores que podrían explicar aquello. Primero, la frontal arremetida del gobierno contra la oposición y su subsecuente victoria, que abrió paso a la convocatoria a una consulta popular sobre la instalación de una Asamblea Constituyente (AC), permitió que el descontento popular contra los partidos políticos y el Congreso sea canalizado a través mecanismos electorales. Segundo, el gobierno fue fiel a sus ofrecimientos de campaña, no sólo limitándose a sus promesas de enfrentar a la partidocracia y de convocar a la AC sino que incluyó acciones muy concretas como sus esfuerzos por controlar los abusos de la banca y de las empresas de telefonía móvil; aumentar la participación del Estado en las utilidades de los excedentes del precio del petróleo; revisar las concesiones mineras; la reafirmación de no renovar el contrato de la base de Manta con el gobierno norteamericano, entre otras (Hoy on line, 2007a). Tercero, en un contexto de abundancia de recursos petroleros, y motivado por consideraciones electorales, el gobierno llevó una política populista de generoso gasto social que ensanchó su base de apoyo y neutralizó cualquier intento de oposición. Esto incluyó, entre otras cosas, el aumento de 15 a 30 dólares en el Bono de Desarrollo Humano; el incremento en el Bono de la Vivienda de 1.800 a 3.600 dólares en áreas urbanas y de 500 a 3.600 en áreas rurales; $50 \%$ de subvención en el precio de la úrea; rebaja en la tarifa eléctrica a los consumidores más pobres; 10 años de plazo adicionales al campesinado para el pago de sus deudas con el Banco Nacional de Fomento, y eliminación de la "donación" de 25 dólares para el acceso a la educación básica (International Crisis Group, 2007; Revista Vistazo, 2007a, Hoy on line, 2007b). Cuarto, la cooptación dentro del gobierno de movimientos sociales de izquierda y la colaboración con el movimiento indígena.

\section{Coyuntura económica}

Los indicadores macroeconómicos del 2007 reflejan una marcada desaceleración económica. Ello pese a los altos precios del petróleo y al incremento en el monto total de remesas de los migrantes (RTU, 2007a; DW-World.De, 2008). La explicación reside en una importante caída de la producción petrolera que se expresa en un PIB petrolero negativo que pasó de $-4,6 \%$ en el 2006 a $-9,8 \%$ en el 2007, así como por un descenso en la tasa de crecimiento del PIB no petrolero que pasó de 6,2\% en el 2006 al 4,4\% en el 2007 (El Hoy on line, $2008 \mathrm{ab}$ ). El crecimiento del PIB fue de 2,65. Este es el crecimiento más bajo experimentado por el país desde el proceso de dolarización en el año 2000, y sitúa al país en la cola de Sudamérica, y muy por debajo del promedio de 5,6\% de América Latina. (El hoy on line, 2008c). Este dato es significativo si se considera que en el Ecuador tradicionalmente ha existido una correlación positiva entre precio del petróleo y crecimiento económico. Esta relación se invierte en el 2007 a pesar de que el valor promedio del barril de petróleo fue de 74 dólares, más del doble de lo presupuestado en la proforma del Estado, y superior

2 El término 'partidocracia', acuñado por Correa en las elecciones presidenciales del 2006, es genérico y hace referencia a los partidos políticos del sistema sin distinción, pero con especial énfasis en los partidos tradicionales tales como el Partido Social Cristiano (PSC), Izquierda Democrática (ID), Partido Roldosista Ecuatoriano (PRE) y Unión Demócrata Cristiana (UDC) que es la ex Democracia Popular (DP). Por extensión a ellos se suman también los dos partidos populistas emergentes: Partido Renovador Institucional Acción Nacional (PRIAN) y Partido Sociedad Patriótica (PSP). 
también al promedio de 50,75 en 2006 (Banco Central del Ecuador, 2007ª). La inflación anual que venía en un proceso decreciente se incrementó con respecto al 2006 y cerró en 3,32\%. Este promedio hubiese sido mayor de no mediar el aumento de precios en los derivados de combustible y la dependencia del Ecuador que importa hasta un $60 \%$ de su consumo, lo que de alguna manera neutralizó el excesivo gasto fiscal. No obstante, ello tuvo su consiguiente impacto negativo en la caja fiscal (Salazar, 2008). La balanza comercial también ha disminuido en cerca de un $11 \%$ con respecto al 2006, principalmente por la caída en la producción del petróleo y un incremento de las importaciones (Salazar, 2008; El Diario.com.ec, 2007; Hoy on line, 2007c).

\section{Coyuntura subregional e internacional}

A nivel de la subregión destaca el fortalecimiento de los lazos de cooperación, principalmente energética con Venezuela, el rol proactivo del país en iniciativas de integración subregional y las tensas relaciones con Colombia. Desde inicios de año el acercamiento con Venezuela en materia energética se vuelve tangible y adquiere nuevas dimensiones. Hasta el mes de mayo se firmaron doce acuerdos, diez de los cuales son en materia energética (El tiempo.com, 2007). Destaca el refinamiento de crudo en Venezuela, la futura construcción de una refinería con un costo de cinco mil millones de dólares y el alquiler de torres de perforación petrolera a precios simbólicos (Explored, 2007a; Hoy on line, 2007de). Como contrapartida, el Ecuador se ha convertido en un aliado de Venezuela en la integración subregional. El impulso del Ecuador fue importante en la fundación del Banco del Sur (El Universo.com, 2007); apoyó públicamente la Alternativa Bolivariana para los Pueblos de Nuestra América (ALBA) (Ecuadorinmediato, 2007ª); sugirió y respaldó al ex presidente Rodrigo Borja para ocupar el cargo de Secretario General de la recientemente creada Unión de Naciones Sudamericanas (Unasur); y logró que su sede sea la ciudad de Quito (Explored, 2007b). Las relaciones con Colombia se caracterizaron nuevamente por una constante tensión. El Ecuador reafirmó su política de neutralidad y no involucramiento en el conflicto colombiano. La tensión se reflejó en el hecho que el Ecuador permaneció sin representante en Colombia desde el mes de diciembre del 2006, cuando su Embajador fuera llamado a consulta, hasta el mes de septiembre en que, en medio de un inquietante dilatamiento, el gobierno colombiano dio el beneplácito al nuevo Embajador propuesto (Hoy on line, 2007f) El incumplimiento de Colombia a los acuerdos relacionados con las fumigaciones aéreas (Explored, 2007c), así como la reiterada violación al territorio ecuatoriano por parte del Ejército y de las fuerzas irregulares fueron los temas más tensionantes. La respuesta ecuatoriana fue la amenaza de demandar a Colombia ante la Corte Internacional de La Haya para que asuma y pague los daños ocasionados por las aspersiones con glisofato (Hoy on line, 2007g), y el reforzamiento militar de la frontera norte (El Universo, 2007 $)^{3}$

3 El Estado ecuatoriano ha solicitado reiteradamente a Colombia que paralice y asuma las perniciosas consecuencias que las aspersiones aéreas con glisofato para erradicar sembríos de cocas en la zona fronteriza común que tiene para la salud y cultivos de sus nacionales. La decisión unilateral del gobierno colombiano de reiniciar las aspersiones aéreas el 12 de diciembre de 2006, desconociendo así el acuerdo de suspensión 
En lo internacional destaca una política más soberana frente a Estados Unidos y los organismos de Breton Wood, y una política de fortalecimiento del multilateralismo. Al ser Estados Unidos el principal socio comercial del Ecuador, destaca la importancia de haber logrado una extensión de las preferencias arancelarias (ATPDEA) hasta febrero del 2008 (Hoy on line, 2007h). No obstante, las relaciones han estado marcadas por un significativo alejamiento ecuatoriano que se ha expresado, por ejemplo, en la expulsión del delegado del Banco Mundial (El Mercurio, 2007), los anuncios de no renovación del acuerdo de la Base de Manta (Hoy on line, 2007i), la amenaza de denunciar el Tratado de Promoción y Protección Recíproca de Inversiones (Hoy on line, 2007jk), y la ratificación de no interés en un Tratado de Libre Comercio (Hoy on line, 2007l). Por el lado norteamericano destaca la decisión de cambiar la sede de las maniobras militares Unitas que debían desarrollarse en Ecuador, a lo que Ecuador respondió con su no participación en ellas (BBC Mundo.com, 2007). En este contexto se subraya la visita del Subsecretario de Estado Norteamericano John Negroponte al Ecuador para tratar alguno de estos temas (Noticias del Sur, 2007). El distanciamiento con Estados Unidos tuvo su contraparte en la búsqueda de nuevos socios estratégicos entre los que destaca el acercamiento del Ecuador con Irán (Los Tiempos.com, 2007) y el fortalecimiento de las relaciones con China en el área energética (Ecuadorinmediato, 2007b). Otro tema importante es el reingreso del Ecuador a la Organización de Países Productores de Petróleo (OPEP) (El País.com, 2007) y el fallo de la Organización Mundial de Comercio (OMC) a favor del Ecuador en su disputa con la Unión Europea por el tema de los aranceles al banano (Soitu.es, 2007).

\section{Coyuntura política}

El año 2007 fue un año eminentemente político y electoral que giró en torno al proceso de convocatoria, elección e instalación de una Asamblea Constituyente (AC). Cada una de estas etapas tuvo lógicas distintas teniendo como denominador común tan sólo las reiteradas victorias del gobierno y la incapacidad de la "partidocracia" para articular una coherente oposición. En buena medida ello fue función de la capacidad del presidente Correa para canalizar a su favor la enorme frustración de la sociedad con respecto a la dinámica política, fundamentalmente frente a los partidos políticos y sus prácticas corruptas y prebendalistas. En este proceso el gobierno pasó en tan sólo nueve meses del extremo límite de las situaciones minoritarias, al no contar con ningún contingente legislativo propio en el Congreso, a una situación de poder extremo al lograr el control absoluto de una AC de plenos poderes (Para datos de conformación parlamentaria y de la AC ver Tablas 2 y 5 respectivamente). El telón de fondo fue siempre una profunda polarización política y social exitosamente inducida por el gobierno. Ella le permitió cosechar asombrosos triunfos electorales así como evitar se ponga en evidencia la carencia de una propuesta concreta de reformas. Destaca también una estrategia de "cooptación" 
de las Fuerzas Armadas a través de la asignación de contratos y de su involucramiento en áreas estratégicas estatales.

La etapa de convocatoria se caracterizó por una frontal confrontación entre el gobierno -apoyado predominantemente por pequeños partidos de izquierda- y la denominada mayoría anticonstituyente -conformada por el Partido Renovador Institucional Acción Nacional (PRIAN), el Partido Sociedad Patriótica (PSP), el Partido Social Cristiano (PSC) y la Unión Demócrata Cristiana (UDC)- y que controlaba cerca del 70\% de los escaños del Congreso. Destacó también la habilidad del gobierno para trasladar oportunamente el conflicto político desde la arena formal a las calles. Esto le permitió compensar su debilidad en la arena formal con un masivo respaldo popular basado en sus altos índices de popularidad y confianza, pero sobre todo en la aversión ciudadana hacia los partidos políticos y el Congreso (Hoy on line, 2007m). Ya con anterioridad a la instalación del nuevo Congreso el 5 de enero, la mayoría opositora advirtió que no daría paso a una consulta popular sobre la instalación de una AC que reforme a la Constitución y que constituyó la principal oferta de campaña del gobierno entrante (El Universo, 2007b). Ello quedó muy en claro con la temprana e ilegal destitución de dos diputadas del PSP que apoyaron abiertamente la convocatoria (Hoy on line, 2007n).

Sin embargo, la oportunista actitud del PSP, que en su condición de segunda fuerza legislativa jugaba un rol de fiel de la balanza, abrió un resquicio muy bien aprovechado por el gobierno para que finalmente la convocatoria a la consulta sea aprobada. Este proceso de convocatoria, en el que fue involucrado y resultó jugando un rol preponderante el Tribunal Supremo Electoral (TSE), puso nuevamente de relieve las características propias de la dinámica política ecuatoriana basadas en el prebendalismo, la conformación de alianzas fantasmas (Mejía, 2006), la constante recurrencia a interpretaciones constitucionales y la ilegalidad (Crisis Group, 2007; Clacso, 2007). Esto último adquiriría mayores dimensiones con la inconstitucional sustitución del presidente del TSE por parte de la mayoría anticonstituyente por haber viabilizado la convocatoria; y la inmediata reacción del TSE que destituyó a los 57 diputados que votaron dicha resolución. ${ }^{4}$ La resolución del TSE se basó en una ley que establece que durante los procesos electorales el TSE es la máxima autoridad del país y le otorga la facultad de destituir a cualquier autoridad que trate de entorpecer el proceso (art. 155, e, Ley Orgánica de Elecciones). A la postre, la principalización de 21 diputados suplentes agrupados en un bloque denominado de la "Dignidad Nacional", que se alineó parcialmente con el gobierno, alteró la correlación de fuerzas en el Congreso y otorgó un importante respiro al gobierno (Hoy on line, 2007p). Los acontecimientos electorales posteriores debilitarían aún más a la ya exigua oposición con lo que el Congreso asumió

4 A la base de este conflicto se encuentra la ambivalente actitud del PSP frente al gobierno. Al parecer, el partido liderado por el ex Presidente Lucio Gutiérrez condicionó su apoyo a la AC al control de la Contraloría General del Estado y de la Fiscalía General de la Nación (Hoy on line, 2007º, Mejía, 2008). El PSP no sólo tenía capacidad para actuar como fiel de la balanza en el Congreso Nacional sino también en el Tribunal Supremo Electoral (TSE), organismo que al parecer tenía también la facultad de viabilizar el llamado a consulta, y que lo presidía Jorge Acosta, vocal designado por el propio partido. No obstante, una vez conseguido el control de estos organismos de control, el PSP dio la espalda al gobierno. Posteriormente, y un movimiento estratégico, el gobierno logró alinear al presidente del TSE con la minoría y viabilizó el llamado a consulta. 
un rol secundario en una arena política que en lo sucesivo fue dominada por la figura del presidente Correa. No obstante, la cadena de ilegalidades y conflicto iniciado con la destitución de los diputados no quedaría allí. Los diputados destituidos interpusieron una serie de recursos de amparo en cuyo examen primarían más lógicas partidistas y de poder que estrictamente jurídicas. Dichos recursos serían aceptados por el Juez 15 de lo Penal del Guayas, Juan Ramírez, y por el TC. La aceptación de este último se dio en momentos en que su permanencia en el cargo estaba siendo discutida en el Congreso, controlado ya por la nueva mayoría, bajo el argumento de que sus vocales se hallaban en funciones prorrogadas. Ello les valdría su inmediata destitución, el primero a manos del TSE con base a la misma norma de la Ley de Elecciones mencionada, y el segundo a manos del Congreso. El ciclo se cerraría cuando a finales de abril la Jueza 18 de lo Penal de Pichincha, Elsa Sánchez de Melo, acoge la petición de la Fiscal de Pichincha, Elsa Moreno, y dispone la prisión preventiva de 24 de los 57 legisladores destituidos bajo el cargo de sedición y de atribuirse la calidad de legisladores que ya no les corresponde. Dicha providencia, que el presidente Correa declaró públicamente como de inoportuna, tuvo su origen en una demanda presentada por los legisladores del bloque de la "Dignidad Nacional" (Agencia de Noticias de la Policía del Ecuador, 2007).

Con posterioridad a ello se inicia una frenética etapa electoral que concluyó con aplastantes triunfos del gobierno en la Consulta Popular sobre el llamado a una AC convocada para el 15 de abril y la posterior elección de asambleístas realizada el 30 de septiembre. Esta última marcaría la virtual desaparición de los partidos políticos y del precario sistema de partidos existente. Estos dos triunfos electorales de Correa se apuntalaron nuevamente en un radical discurso contra la 'partidocracia' y la alta popularidad del presidente. A ello se sumó un generoso gasto social que abonó también en buena medida sus apabullantes victorias electorales. En términos generales ambas elecciones transcurrieron con normalidad y libres de las tradicionales acusaciones de fraude (Centro Carter, 2007). No obstante, el TSE tuvo que intervenir para prohibir al gobierno el uso de fondos públicos con fines proselitistas (RTU, 2007b). La popularidad y confianza en el presidente tuvo un breve traspié a mediados de año cuando se difundieron los denominados "patiñovideos" (Cedatos, 2007). En una de esas grabaciones se ve al ministro de Economía Ricardo Patiño y al ex ministro del anterior gobierno Armando Rodas, conversando con miembros de la compañía Abadi\&Co, tenedora de bonos de deuda externa, sobre la posibilidad de especular en el mercado internacional a través del anuncio del no pago de los bonos denominados Global 2030. Un segundo video muestra al mismo ministro en una reunión privada con el presidente del Congreso Jorge Cevallos en la que se trata sobre temas relacionados con la aprobación de la convocatoria a AC por parte del Congreso. Al final de la reunión este último pregunta por el estado de un contrato público que necesitaba la autorización del presidente (Presidencia de la República, 2007). Este acontecimiento terminaría con la censura del ministro por parte del Congreso el día 13 de julio pero para posteriormente ser nombrado por el presidente ministro del Litoral.

La instalación de una Asamblea Constituyente con plenos poderes el 29 de noviembre controlada totalmente por el presidente Correa a través de MPAIS dejó vía libre para que el gobierno pueda llevar adelante su proyecto político. Sin embargo, ante la ausencia 
de una agenda concreta de reformas --más allá de las vagas y continuas referencias al Socialismo del siglo XXI y la presentación de una propuesta gubernamental para debate sobre la que no se ha debatido- en la práctica la Asamblea ha relegado a segundo plano la discusión de reformas constitucionales, lo que ha terminado desvirtuando su naturaleza. En su lugar, y a través de interpretaciones muy cuestionables acerca los estatutos que rigen su funcionamiento y poderes, ella ha sido utilizada como un mecanismo político para erradicar cualquier vestigio de oposición en los órganos e instituciones del Estado y se ha arrogado funciones legislativas que no le corresponden. Es así que al día siguiente a su instalación la Asamblea Constituyente dicta su primer mandato por el cual, entre otras cosas, suspende indefinidamente al Congreso Nacional, asume formalmente las funciones de éste, y reemplaza al ministro Fiscal y Superintendente de Bancos (Hoy on line, 2007q). Es en esta misma tónica que el 28 de diciembre la Asamblea aprueba una reforma tributaria mediante la Ley de Equidad Financiera, al tiempo que informa del tratamiento de otras iniciativas legislativas (Hoy on line, 2007r).

Es importante también destacar lo que parece ser una estrategia gubernamental orientada a congraciarse con las Fuerzas Armadas a través del otorgamiento de importantes concesiones. De hecho, en un país políticamente tan inestable como el Ecuador y caracterizado por una debilidad institucional crónica, las Fuerzas Armadas han jugado un rol fundamental en situaciones de crisis. Como lo anota Mejía (2008), en momentos de crisis las Fuerzas Armadas se toman atribuciones que constitucionalmente nos les corresponden al pronunciarse sobre decisiones que recaen exclusivamente en la esfera política. ${ }^{5}$ Estas concesiones han sido realizadas fundamentalmente al amparo de los decretos de emergencia expedidos por el gobierno en áreas específicas como la vial y energética y que han posibilitado la contratación directa con el Ejército y la Marina, así como el encargo del control de la empresa petrolera estatal a esta última (Explored, 2007d; Hoy on line, 2007s).

\section{CAMBIOS INSTITUCIONALES Y CAMBIOS SUBSTANCIALES EN POLÍTICAS PÚBLICAS}

El 2007 no fue un año de mayores cambios en políticas públicas. Los resultados de la batalla entre el gobierno y la oposición permiten más bien caracterizarlo como un año de acomodo de la arena política para que el gobierno pueda pasar su paquete de reformas, incluida la adopción de una nueva Constitución, en el 2008. No obstante, a nivel Ejecutivo fue un año de intensa reestructuración funcional que incluyó cambios en instituciones y ministerios. Las primeras reflejan un cambio radical en la forma de entender el rol del Estado en el desarrollo y la economía, y que ponen el acento en sus funciones de planificación, regulación, control y distribución (Revista Vanguardia, 2007a) y las segundas orientadas a dotar de mayor eficiencia al Poder Ejecutivo (Hoy on line, 2007t). Entre las primeras

5 Por ejemplo, la misma fuente nota, sobre la base de un documento de la Comisión Andina de Juristas, que en la caída de Gutiérrez si bien las fuerzas armadas ratificaron su naturaleza de ser obedientes y no deliberantes, en la práctica no reconocieron la designación del vicepresidente Palacios como nuevo presidente sino después de varias horas (Mejía, 2008) 
destaca la eliminación del Consejo Nacional de Modernización del Estado (CONAM) y de la Secretaría Nacional de los Objetivos del Milenio (Sodem) que se fusionaron en una reestructurada y fortalecida Secretaría Nacional de Planificación y Desarrollo (Senplades) (Hoy On line, 2007u). Ésta, junto con la Secretaría General de la Administración Pública, serán las encargadas de coordinar la gestión del Plan Nacional de Desarrollo 2007-2010 del gobierno. La reestructuración ministerial incluyó la creación de seis ministerios coordinadores de mayor nivel jerárquico llamados a articular y coordinar las actividades de los hoy llamados ministerios sectoriales; la creación de seis nuevos ministerios sectoriales, de los cuales dos por escisión de uno antiguo; los cambios de nombre a las carteras de Estado; y la desaparición del Ministerio de Comercio Exterior cuyas funciones pasaron al Ministerio de Relaciones Exteriores (ver sección IV). Destaca también la creación de cinco secretarías cuyos titulares tienen rango de Ministros de Estado. Ellas son la Secretaría Nacional Anticorrupción (Creada 16/02/07); Secretaría de Pueblos, Movimientos Sociales y Participación (26/02/2007), Secretaría Nacional de Migrante (01/03/2007), Secretaría de Coordinación Institucional (02/05/2007) y la Secretaría General de la Presidencia (18/10/2007) (Presidencia de la República, 2007b). Adicionalmente, destaca la presentación por parte del gobierno del "Plan Ecuador" que potencialmente podría tener un impacto significativo en la relaciones colombo-ecuatorianas y la cooperación externa frente a las secuelas del conflicto colombiano. Ésta ha sido calificada como una propuesta de paz frente al Plan Colombia y consiste en una iniciativa social de desarrollo en la frontera norte en la que se incluye la regularización y atención a los desplazados colombianos (Ministerio de Relaciones Exteriores, 2007). Ello implicaría a la postre la eliminación de la Unidad para el Desarrollo de la Frontera Norte (UDENOR) (CRE Satelital, 2007).

\section{RESULTADOS DE ELECCIONES}

Los procesos electorales del 2007 constituyen la culminación de un proceso de deslegitimación democrática y marcan un punto de quiebre radical en el sistema político y la desaparición del sistema de partidos ecuatoriano existente desde 1979. El primer proceso fue el llamado a Consulta Popular del día 15 de abril sobre la instalación de una Asamblea Constituyente y el segundo, la elección de asambleístas realizada el 30 de septiembre. Estos dos procesos se caracterizaron por un excesivo personalismo en la medida en que el presidente Rafael Correa fue la figura central que los motivó y en torno al que ellos se desarrollaron. Sin embargo, aunque la habilidad política del presidente Correa fue determinante para que dichos procesos sean convocados, los resultados electorales se inscriben en una lógica de protesta contra la política tradicional y las instituciones democráticas. De allí que el rotundo éxito electoral del presidente Correa haya residido principalmente en su capacidad para sintonizar la frustración ciudadana y encarnar la esperanza de cambio. No extraña, por lo tanto, que los dos procesos electorales se caracterizaran por la ausencia de debate y la falta de propuestas. La estrategia principal del gobierno consistió simplemente en amplificar muy hábilmente la aversión ciudadana hacia los partidos políticos y el Congreso, y vender la idea de que la Asamblea Constituyente sería el mecanismo para liquidarlos. A ello también coadyuvó la alta popularidad del presidente y la confianza generada por el 
fiel cumplimiento a sus promesas de campaña desde el mismo inicio de su gobierno. No hay que olvidar tampoco la inmejorable coyuntura económica que posibilitó un generoso gasto social, en especial a nivel de subsidios, que terminaría adquiriendo fuertes tintes populistas tal como lo muestra el Gráfico 1. En un país donde el voto descansa mucho en redes clientelares, la gran interrogante que queda es la de si este enorme gasto social se tornó en una suerte de equivalente funcional de la apropiación de redes clientelares, el mismo que terminaría desplazando a estas últimas, o si la estrategia del gobierno incluyó ambas.

Grafico 1: Evolución de los subsidios en los últimos cinco años

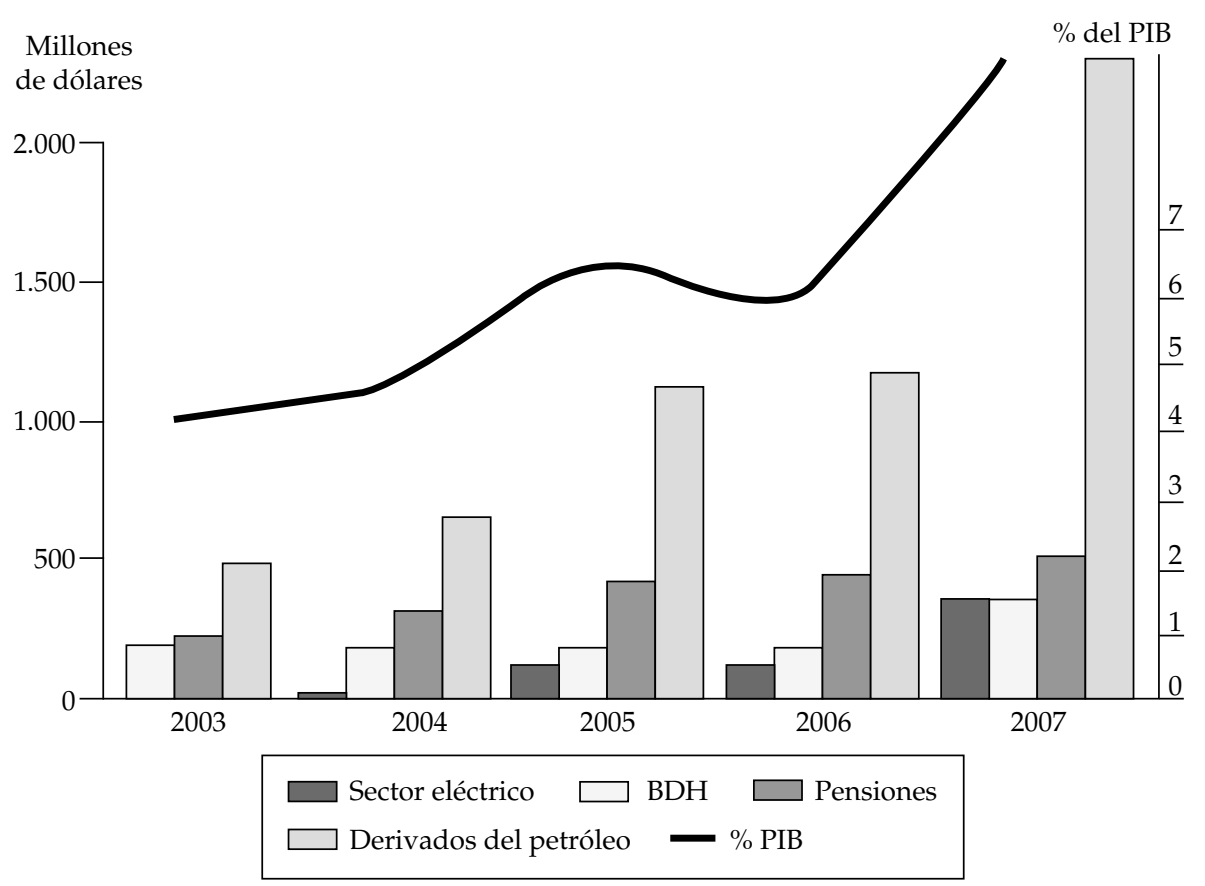

Fuente: Gráfico tomado de Grupo Faro, 2007: 6.

Nota: Los datos del 2007 corresponden al presupuesto inicial aprobado para el año 2007, no al presupuesto codificado. Las iniciales BDH hacen referencia al Bono de Desarrollo Humano.

La propuesta de Correa de llamar a una Asamblea Constituyente contó con el respaldo mayoritario de cerca del 82\% de la población (Tabla 1). Adicionalmente a los factores ya enunciados, el erróneo accionar de los partidos en el Congreso durante el tortuoso proceso de convocatoria pudo también haber incidido en el abrumador resultado al otorgar al gobierno una base inmejorable para profundizar la ya extrema polarización. Se destaca el bajo porcentaje de votos blancos y nulos que es menor a $6 \%$, cifra muy inferior al $30 \%$ que fue el promedio en las seis consultas realizadas durante el actual período democrático (Pachano, 2007a). A la postre esta elección marcaría el inicio del fin del sistema de partidos. 
Tabla 1: Pregunta y resultados de la consulta popular del 15 de abril de2007

Pregunta: ¿Aprueba usted, que se convoque e instale una Asamblea Constituyente con plenos poderes de conformidad con el Estatuto Electoral que se adjunta, para que transforme el marco institucional del Estado y elabore una nueva Constitución?

\begin{tabular}{|c|c|c|c|c|c|}
\hline & \multicolumn{3}{|c|}{ TOTAL } & \multicolumn{2}{|c|}{$\%$ TOTAL } \\
\hline Votos "SÍ & \multicolumn{3}{|c|}{5.354 .595} & \multicolumn{2}{|c|}{$81,72 \%$} \\
\hline Votos "NO" & \multicolumn{3}{|c|}{814.323} & \multicolumn{2}{|c|}{$12,43 \%$} \\
\hline Votos Nulos & \multicolumn{3}{|c|}{332.484} & \multicolumn{2}{|c|}{$5,07 \%$} \\
\hline Votos Blancos & \multicolumn{3}{|c|}{51.087} & \multicolumn{2}{|c|}{$0,78 \%$} \\
\hline \multicolumn{6}{|c|}{ INFORMACIÓN ADICIONAL } \\
\hline & Total & Hombres & $\%$ & Mujeres & $\%$ \\
\hline Electores Registrados & 9.188 .787 & 4.555 .458 & $49,58 \%$ & 4.633 .329 & $50,42 \%$ \\
\hline Juntas Electorales & 36.873 & 18.215 & $49,40 \%$ & 16.658 & $50,60 \%$ \\
\hline Sufragantes & 6.578 .224 & 3.198 .121 & $48,62 \%$ & 3.380 .103 & $51,38 \%$ \\
\hline Ausentismo & & & $30,12 \%$ & & $27,29 \%$ \\
\hline
\end{tabular}

Fuente: Elaboración del autor a partir de datos del Tribunal Supremo Electoral (TSE).

La elección de candidatos a la Asamblea Constituyente significó el golpe de gracia al sistema de partidos. En ella se eligieron 130 representantes repartidos de la siguiente forma: 24 electos en circunscripción nacional; 100 electos en distritos provinciales; y por primera vez se otorgó representación a los migrantes ecuatorianos de USA y Canadá; Europa y Latinoamérica, que eligieron de entre ellos 6 asambleístas a razón de dos por cada una de estas regiones. En el distrito nacional y en los provinciales que eligen más de dos candidatos el sistema electoral utilizado fue el proporcional con voto combinado (panachage) y con el método Hare para la asignación de escaños; en los distritos provinciales cuya magnitud es de dos se estableció que el primer escaño correspondería a la lista más votada y el segundo a aquella que le siga en votos siempre y cuando obtenga al menos el $20 \%$ de los votos alcanzados por la primera; para los ecuatorianos residentes en el exterior se estableció un sistema de pluralidad que acordaba el escaño a los dos candidatos más votados (TSE, 2007). Cada elector, incluido los ecuatorianos residentes en el exterior, tuvo la posibilidad de elegir sus representantes nacionales más aquellos de su circunscripción electoral. Una fuente destaca, en base a datos proporcionados por el TSE, la presencia de 150 listas autorizadas a competir ya sea a nivel nacional o provincial, cifra que no incluye las listas que compiten en el exterior (Pachano, 2007b). La misma fuente destaca que 116 de ellas competirán en una sola circunscripción sea esta nacional o a nivel de alguna provincia. El número de candidaturas mencionada responde a la inscripción de un altísimo número de candidaturas independientes, sobre todo a nivel provincial, que confiaban en beneficiarse de la agonía de los partidos tradicionales.

Cabe destacar que la debacle del sistema de partidos fue muy difícilmente predecible. Si bien podía esperarse que los partidos tradicionales como el PSC, ID, DP-UDC y PRE continúen perdiendo el exiguo espacio electoral que les restaba, se esperaba que los beneficiarios de ello sean nuevamente las agrupaciones populistas emergentes como el 
PRIAN y el PSP (Machado, 2007). Sin embargo, ello no sucedió. Los partidos emergentes, incluso el partido indígena MUPP-NP, fueron severamente castigados por los electores. Este último tuvo su más discreta participación electoral de su historia con tan sólo dos escaños en solitario y tres en alianzas con otros partidos. La atipicidad en los resultados de estas elecciones, por lo tanto, se muestra principalmente en la forma cómo el presidente Correa y su movimiento (MPAIS) fueron capaces de superar la tradicional y altísima fragmentación ecuatoriana al conseguir en solitario 73 escaños de los 130 posibles, a los que se adicionan 7 asambleístas electos en alianzas (Tabla 2).

Para tener una idea de la magnitud de los cambios producidos hay que recordar que en las elecciones legislativas para el período 2002-2006 los cuatro partidos tradicionales, ya para entonces en franco retroceso, alcanzaron el 53\% de escaños en el Congreso; las fuerzas emergentes del PRIAN y el PSP lograron conjuntamente el 13\%, y el MUPP-NP un 10\%. Cuatro años más tarde, en las elecciones del 2006 la sumatoria de los cuatro partidos tradicionales alcanzó tan sólo un 31\%. En esa ocasión el PRIAN y el PSP parecían perfilarse como los herederos de estos últimos al obtener conjuntamente el $52 \%$ de los escaños. MUPPNP vería también descender su cuota legislativa a un magro 6\% (Machado, 2007). En la elección de Asambleístas del 2007, los partidos tradicionales alcanzan un poco más del $5 \%$ de los escaños en la Asamblea, el PRIAN y el PSP tan sólo el 20\% y la representación del MUPP-NP no llega sino al 1,5\%.

La votación de MPAIS, por lo tanto, no sólo refleja la votación más alta jamás alcanzada por una organización política -de hecho la primera vez que un partido alcanza la mayoría absoluta de votos- sino que además le otorga un control total de la Asamblea Constituyente cuyas decisiones requieren tan sólo de la mayoría simple de votos (Art. 44, Reglamento de Funcionamiento de la Asamblea Constituyente). Debido a la dificultad de agregar los datos a nivel provincial por la cantidad e heterogeneidad de candidaturas compitiendo en cada circunscripción, se adjunta tan sólo los resultados de las votaciones para asambleístas a nivel nacional (Tabla 3). Aunque incompleta, ella da una fotografía muy ilustrativa de lo acontecido en términos de votación. En otro ámbito destaca en esta elección la aprobación de la ley de cuotas por parte del TSE que prevé la conformación de listas en forma alternada y secuencial entre hombres y mujeres (CONAMU, 2007). Como resultado 46 mujeres fueron electas, lo que representa un poco más del 35,3\% del total de la Asamblea. De entre ellas 32 pertenecen a MPAIS; 3 al PSP; 2 al MPAIS/PS-FA; 2 al PRIAN; 2 al PSC; 1 a RED; 1 a UNO; 1 a MHN; 1 a MPAIS/MUSHUK INTI/AA y 1 a MPD/MPAIS.

\section{PODER EJECUTIVO}

El nombramiento y remoción de los ministros de Estado es atribución exclusiva del presidente de la República (art. 171,10 Const.). A partir de 1998 la censura a los ministros por parte del Congreso no entraña su inmediata destitución. Esta es, en última instancia, decidida por el Presidente (Art. 130, 9). Pese a esta reforma constitucional, la inestabilidad del gabinete no se ha reducido en el Ecuador. El año 2007 no constituyó la excepción. A principios de enero, antes de que el actual gobierno asuma funciones, el ministro de Economía y Finanzas 
Tabla 2: Resultados Asamblea Constituyente 2007 por representantes, organizaciones políticas, número y porcentaje de escaños

\begin{tabular}{|c|c|c|}
\hline $\begin{array}{l}\text { Representantes } \\
\text { a elegirse }\end{array}$ & $\#$ & $\begin{array}{l}\text { Agrupaciones políticas que consiguieron } \\
\text { Asambleístas por tipo de representantes }\end{array}$ \\
\hline Nacionales & 24 & MPAIS (15); PSP (2); PRIAN (2); PSC (1); RED (1); (MPD (1); UNO (1); MHN (1) \\
\hline Azuay & 5 & MPAIS (4); PSP (1) \\
\hline Bolívar & 3 & Alianza MPAIS/PS-FA (1); PSP (1), Alianza MUPP-NP/MPD (1) \\
\hline Cañar & 3 & MPAIS (2); PSP (1) \\
\hline Carchi & 3 & MPAIS (2); ID (1) \\
\hline Chimborazo & 4 & MPAIS (2); PSP (1); Alianza ID/MPD/PS-FA/MUPP-NP (1) \\
\hline Cotopaxi & 4 & MPAIS (2); PSP (1); MUPP-NP (1) \\
\hline El Oro & 4 & MPAIS (3); PSC (1) \\
\hline Esmeraldas & 4 & MPAIS (2); PRE (1); MPD (1) \\
\hline Galápagos & 2 & Alianza MPAIS/MIP (1); Alianza PSP/RED (1) \\
\hline Guayas & 18 & MPAIS (10); PSC (2); PRIAN (2); PSP (1); RED (1); MPD (1); UNO (1) \\
\hline Imbabura & 3 & Alianza MPAIS/PS-FA (2); PRIAN (1) \\
\hline Loja & 4 & MPAIS (3); PSP (1) \\
\hline Los Ríos & 5 & MPAIS (3); PRIAN (1); PSP (1) \\
\hline Manabí & 8 & MPAIS (5); PSC (1); PRIAN (1); PSP (1) \\
\hline Morona Santiago & 2 & Alianza MPAIS/MIP (1); PSP (1) \\
\hline Napo & 2 & PSP (1); Alianza MUPP-NP/MNPNS/MOPIN (1) \\
\hline Orellana & 2 & MPAIS (1); PSP (1) \\
\hline Pastaza & 2 & Alianza MPD/MPAIS (1); PSP (1) \\
\hline Pichincha & 14 & MPAIS (9); PRIAN (1); PSP (1); FUTURO YA(1); Alianza ID/MPC (1); RED (1). \\
\hline Sucumbíos & 2 & Alianza MPAIS / Mov. Mushuk Inti/Alianza Amazónica (1); PSP (1) \\
\hline Tungurahua & 4 & MPAIS (3); PSP (1) \\
\hline Zamora Chinchipe & 2 & MPAIS (1); MUPP-NP (1) \\
\hline América Latina & 2 & MPAIS (2) \\
\hline EE.UU. y Canadá & 2 & MPAIS (2) \\
\hline Europa & 2 & MPAIS (2) \\
\hline $\begin{array}{l}\text { Total en escaños } \\
\text { y en porcentaje } \\
\text { de escaños }\end{array}$ & $\begin{array}{l}130 \\
100 \%\end{array}$ & $\begin{array}{l}\text { MPAIS }(73=56,15 \%) ; \text { PSP }(18=13,85 \%) \text {; PRIAN }(8=6,15 \%) \text {; PSC }(5=3,85 \%) ; \\
\text { RED }(3=2,31 \%) ; \text { MPD }(3=2,31 \%) ; \text { Alianza MPAIS/PS-FA }(3=2,31 \%) ; \text { UNO } \\
(2=1,54 \%) ; \text { MUPP-NP }(2=1,54 \%) \text { PSP / RED (1=0,77\%); PRE (1); MUPP-NP / } \\
\text { MPD(1);MUPP-NP/MNPNS/MOPIN (1); MPD/MPAIS (1); MPAIS/MUSHUK } \\
\text { INTI/AA(1); MPAS/MIP (1); MPAIS/MIFA (1); MHN (1); MCIFY (1); ID/ } \\
\text { MPD/PS-FA/MUPP-NP (1); ID/MPC (1); ID (1) }\end{array}$ \\
\hline
\end{tabular}

Observaciones: En América Latina el Número Total de Electores (NTE) fue de 10.211; Sufragantes: 4.745; Votos Blancos: 194; Votos Nulos: 653; en EE.UU. y Canadá el NTE fue de 20.307; Sufragantes: 6.020; Votos Blancos: 196; Votos Nulos: 554; en Europa el NTE fue de 121.662; Sufragantes: 28.933; Votos Blancos: 2.286; Votos Nulos: 6.351. Fuente: Elaboración del autor a partir de datos del TSE. 
Tabla 3: Votos lista cerrada para asambleístas nacionales

\begin{tabular}{|c|c|c|c|c|c|}
\hline Siglas & Organización Política & $\%$ & Total & Votos Hombres & Votos Mujeres \\
\hline PSP & $\begin{array}{l}\text { PARTIDO SOCIEDAD } \\
\text { PATRIÓTICA }\end{array}$ & 7,28 & 294.240 & 145.925 & 148.315 \\
\hline UDC & $\begin{array}{l}\text { UNION DEMÓCRATA } \\
\text { CRISTIANA }\end{array}$ & 0,43 & 17.450 & 8.112 & 9.338 \\
\hline PSC & PARTIDO SOCIAL CRISTIANO & 3,88 & 156.840 & 71.145 & 85.695 \\
\hline PRIAN & $\begin{array}{l}\text { PARTIDO RENOVADOR } \\
\text { INSTITUCIONAL ACCIÓN } \\
\text { NACIONAL }\end{array}$ & 6,62 & 267.605 & 134.44 & 133.171 \\
\hline PRE & $\begin{array}{l}\text { PARTIDO ROLDOSISTA } \\
\text { ECUATORIANO }\end{array}$ & 0,80 & 32.332 & 18.900 & 13.432 \\
\hline PL & PARTIDO LIBERTAD & 0,47 & 19.036 & 10.932 & 8.104 \\
\hline ID/MPC & ALIANZA ID/MPC & 0,54 & 21.759 & 11.133 & 10.626 \\
\hline MPD & $\begin{array}{l}\text { PARTIDO MOVIMIENTO } \\
\text { POPULAR DEMOCRÁTICO }\end{array}$ & 1,68 & 68.060 & 33.022 & 35.038 \\
\hline $\begin{array}{l}\text { PS-FA/ } \\
\text { MUPP-NP }\end{array}$ & ALIANZA PSFA/MUPP-NP & 0,71 & 28.635 & 14.722 & 13.913 \\
\hline C4 & $\begin{array}{l}\text { MOVIMIENTO COMPROMISO } \\
\text { CÍVICO CRISTIANO CON LA } \\
\text { COMUNIDAD. C4 }\end{array}$ & 0,39 & 15.594 & 6.014 & 9.580 \\
\hline $\mathrm{MCN}$ & $\begin{array}{l}\text { MOVIMIENTO CONCILIACIÓN } \\
\text { NACIONAL }\end{array}$ & 0,29 & 11.663 & 4.946 & 6.717 \\
\hline MHN & $\begin{array}{l}\text { MOVIMIENTO HONRADEZ } \\
\text { NACIONAL }\end{array}$ & 0,70 & 28.198 & 9.821 & 18.377 \\
\hline RED & $\begin{array}{l}\text { MOVIMIENTO RED ÉTICA Y } \\
\text { DEMOCRACIA }\end{array}$ & 2,00 & 80.927 & 33.552 & 47.375 \\
\hline MANA & $\begin{array}{l}\text { MOVIMIENTO DE ACUERDO } \\
\text { NACIONAL }\end{array}$ & 0,65 & 26.358 & 12.777 & 13.581 \\
\hline MPAIS & $\begin{array}{l}\text { MOVIMIENTO PATRIA ALTIVA Y } \\
\text { SOBERANA }\end{array}$ & 69,47 & 2.806 .004 & 1.392 .883 & 1.413 .121 \\
\hline MBERP & $\begin{array}{l}\text { MOVIMIENTO BLANCO } \\
\text { ECUATORIANO POR LA } \\
\text { REIVINDICACIÓN DE LOS } \\
\text { POBRES }\end{array}$ & 0,44 & 17.813 & 8.754 & 9.059 \\
\hline MIJS & $\begin{array}{l}\text { MOVIMIENTO INDEPENDIENTE } \\
\text { JUSTO Y SOLIDARIO }\end{array}$ & 0,20 & 7.883 & 3.820 & 4.063 \\
\hline UNO & UNA NUEVA OPCIÓN, UNO & 1,12 & 45.127 & 17.080 & 28.047 \\
\hline MILC & $\begin{array}{l}\text { MOVIMIENTO INDEPENDIENTE } \\
\text { LAICOS COMPROMETIDOS }\end{array}$ & 0,43 & 17.264 & 6.460 & 10.804 \\
\hline $\begin{array}{l}\text { MCSXXI/ } \\
\text { MAE/MTF }\end{array}$ & ALIANZA MCSXXI/MAE/MTF & 0,38 & 15.279 & 6.105 & 9.174 \\
\hline MIPD & $\begin{array}{l}\text { MOVIMIENTO INDEPENDIENTE } \\
\text { POLO DEMOCRÁTICO }\end{array}$ & 0,32 & 13.037 & 6.653 & 6.384 \\
\hline
\end{tabular}


Continuación Tabla 2

\begin{tabular}{|c|c|c|c|c|c|}
\hline Siglas & Organización Política & $\%$ & Total & Votos Hombres & Votos Mujeres \\
\hline MCND & $\begin{array}{l}\text { MOVIMIENTO CONCERTACIÓN } \\
\text { NACIONAL DEMOCRÁTICA }\end{array}$ & 0,33 & 13.285 & 6.951 & 6.334 \\
\hline MNCS & $\begin{array}{l}\text { MOVIMIENTO NACIONAL POR } \\
\text { LA CONCERTACIÓN SOCIAL }\end{array}$ & 0,17 & 7.026 & 3.265 & 3.761 \\
\hline MITS & $\begin{array}{l}\text { MOVIMIENTO DE } \\
\text { INTEGRACIÓN Y } \\
\text { TRANSFORMACIÓN SOCIAL }\end{array}$ & 0,12 & 4.718 & 2.130 & 2.588 \\
\hline MFE & $\begin{array}{l}\text { MOVIMIENTO FUERZA } \\
\text { ECUATORIANA }\end{array}$ & 0,41 & 16.445 & 8.785 & 7.660 \\
\hline MTM & MOVIMIENTO TRIUNFO MIL & 0,17 & 6.815 & 3.353 & 3.462 \\
\hline \multicolumn{6}{|c|}{ INFORMACIÓN ADICIONAL } \\
\hline & Total & Hombres & $\%$ & Mujeres & $\%$ \\
\hline $\begin{array}{l}\text { Electores } \\
\text { Registrados }\end{array}$ & 9.371 .232 & 4.642 .289 & 49,54 & 4.728 .943 & 50,46 \\
\hline $\begin{array}{l}\text { Juntas } \\
\text { Electorales }\end{array}$ & 37.656 & 18.588 & 49,36 & 19.068 & 50,64 \\
\hline Sufragantes & 6.857 .466 & 3.337 .596 & 48,67 & 3.519 .870 & 51,33 \\
\hline Votos Blancos & 429.120 & 198.408 & 46,24 & 230.712 & 53,76 \\
\hline Votos Nulos & 665.776 & 300.583 & 45,15 & 365.193 & 54,85 \\
\hline
\end{tabular}

Nota: 7 actas anuladas (210 sufragantes), Fuente: Tablas y datos tomados del TSE y adaptados por el autor

del gabinete del presidente Palacios fue destituido del cargo tan sólo 73 días después de haber sido nombrado (Cueva, 2007). La misma tónica de inestabilidad aguardaba al nuevo gobierno. Pese a que en un inicio destacó la inusual ratificación en sus cargos por parte del gobierno entrante de dos ministros del gobierno saliente (ministras de Turismo y de Ambiente), desde su instalación el 15 de enero hasta el 31 de enero se registraron un total de 43 ministros que deambularon en 27 carteras gubernamentales. En comparación con el año precedente en el que en promedio hubo 1,8 ministros por cartera (29 ministros en un total de 16 carteras), en el 2007 esta cifra fue de 1,6 (Tabla 4). La crónica inestabilidad ministerial en el Ecuador ha estado tradicionalmente asociada a la precariedad de las coaliciones legislativas que arma el presidente (Mejía: 2006). Sin embargo, esto no aplica al gabinete de Correa. Al parecer la permanencia de los ministros en su cargo está más bien asociada al método del trabajo del presidente basado en constantes evaluaciones y resultados (Revista Vanguardia, 2007b). Es posible que a esta inestabilidad contribuya también el liderazgo de tipo personalista del presidente y de su gobierno. Sin embargo, pese a esta inestabilidad, existe un nivel importante de rotación del equipo de gobierno. Ello incluye colaboradores que después de haber abandonado ministerios siguen siendo parte del equipo en otros cargos de la administración (Revista Vanguardia, 2007b). 
El gabinete del presidente Correa es un gabinete atípico en algunos sentidos. Primero, se trata de un gabinete de independientes. Entre los ministros nombrados inicialmente tan sólo cinco tuvieron alguna vinculación partidaria o trayectoria política previa. En su mayoría son personas que vienen del sector académico, de organizaciones sociales y no gubernamentales (International Crisis Group, 2007). Segundo, es un gabinete conformado no sólo en base a factores geográficos, sino también étnicos y de género. Con respecto a este último punto destaca el alto número de ministras y la importancia de los ministerios que ocuparon. Al inicio del gobierno de las 17 carteras de Estado siete estuvieron manejadas por mujeres. Al finalizar el año, este número aumentó a nueve aunque en términos relativos su porcentaje decreció enormemente por la creación de nuevos ministerios. Se trató también de la primera vez en que mujeres fueron escogidas para dirigir el Ministerio de Defensa. Destaca también su nombramiento en ministerios claves como el de Relaciones Exteriores. Tercero, destaca la juventud del gabinete que en su mayoría son personas que apenas superan los cuarenta años (International Crisis Group, 2007).

El estilo de gobierno del presidente Correa podría catalogarse como de corte plebiscitario, confrontacional y autoritario. De hecho, las tres características mencionadas interactuaron y se complementaron con mucho éxito en un contexto eminentemente electoral. La principal fortaleza del gobierno residió en su estrecha relación con la población. Este apoyo ha sido vital para la sobrevivencia del gobierno y para el éxito político alcanzado. Esto no fue fruto del azar. Desde su instalación, la política comunicacional del gobierno se basó en constantes apariciones mediáticas, el permanente recorrido del país a través de los gabinetes itinerantes, y un programa radial sabatino a nivel nacional. La confrontación en su gobierno no se limitó a los partidos políticos sino que incluyó cualquier atisbo de oposición. El carácter autoritario proviene del excesivo personalismo en el liderazgo así como de una radicalidad nada proclive al consenso. Destaca también una propensión a la acumulación del poder que fue más evidente tan pronto como el presidente tuvo el control de la Asamblea. (Rivas y Araque, 2005). Otro constante del gobierno en esta misma dirección fue el de gobernar mediante la declaratoria de estados de emergencia (Hoy on line, 2007v). Pese a que la Constitución sólo permite declarar el estado de emergencia en casos muy puntuales relacionados con seguridad interna o externa y catástrofes naturales (Art. 180 y ss. Constitución) el presidente dictó hasta mediados de noviembre 28 decretos de emergencia en áreas tan diversas como ferrocarriles, educación, vialidad, sector agrícola, migrantes, entre otros. Esto le posibilitó la contratación directa con recursos provenientes de fondos petroleros.

\section{PODER LEGISLATIVO}

El año 2007 fue año aciago para el Poder Legislativo. El conflicto entre el Ejecutivo y el Legislativo -que finalmente involucraría a otros órganos del Estado, incluida la propia Asamblea Constituyente- determinaría cambios drásticos no sólo en la relación de fuerzas al interior del Congreso sino también con respecto sobre su propio rol dentro del sistema político e incluso su posterior eliminación. El día 6 de marzo el TSE resuelve la destitución de 57 de los 70 diputados que conformaban la mayoría anticonstituyente y dejan sin 
Tabla 4: Composición y cambios en el gabinete

\begin{tabular}{|c|c|c|c|c|}
\hline Ministerio & Cambios & Ministros & Período & Datos biográficos \\
\hline $\begin{array}{l}\text { Ministerio de Energía y Minas } \\
\text { (escindido en Ministerio de } \\
\text { Minas y Petróleos, y Ministerio } \\
\text { de Electricidad y Energía } \\
\text { Renovable el }(09 / 07 / 07)\end{array}$ & 1 & Alberto Acosta & $\begin{array}{l}15 / 01 / 07- \\
15 / 06 / 07\end{array}$ & \\
\hline \multirow[b]{2}{*}{$\begin{array}{l}\text { Ministerio de Minas y } \\
\text { Petróleos*(09/07/07) }\end{array}$} & \multirow[b]{2}{*}{2} & Jorge Albán (e) & $\begin{array}{l}09 / 07 / 07- \\
23 / 07 / 07\end{array}$ & \\
\hline & & Galo Chiriboga & $\begin{array}{l}\text { 23/07/07- } \\
\text { actualidad }\end{array}$ & $\begin{array}{l}\text { Masterado en Administración; } \\
\text { Doctor en Jurisprudencia; estudios de } \\
\text { especialización. }\end{array}$ \\
\hline $\begin{array}{l}\text { Ministerio de Electricidad y } \\
\text { Energía Renovable }(09 / 07 / 07)\end{array}$ & 1 & $\begin{array}{l}\text { Alecksey } \\
\text { Mosquera }\end{array}$ & $\begin{array}{l}\text { 09/07/07- } \\
\text { actualidad }\end{array}$ & $\begin{array}{l}\text { Masterado en Gerencia Empresarial; } \\
\text { ingeniero Mecánico; estudios de } \\
\text { especialización. }\end{array}$ \\
\hline \multirow[b]{2}{*}{ Ministerio del Ambiente } & \multirow[b]{2}{*}{2} & Anita Albán & $\begin{array}{l}15 / 01 / 07- \\
15 / 11 / 07\end{array}$ & \\
\hline & & $\begin{array}{l}\text { Marcela } \\
\text { Aguiñaga }\end{array}$ & $\begin{array}{l}15 / 11 / 07- \\
\text { actualidad }\end{array}$ & $\begin{array}{l}\text { Abogada con postgrado en Derecho } \\
\text { Ambiental y Desarrollo Sustentable } \\
\text { y Sostenible, Universidad de } \\
\text { Guayaquil. }\end{array}$ \\
\hline Ministerio de Trabajo y Empleo & 1 & $\begin{array}{l}\text { Antonio } \\
\text { Gagliardo }\end{array}$ & $\begin{array}{l}\text { 15/01/07- } \\
\text { actualidad }\end{array}$ & $\begin{array}{l}\text { Abogado por la Universidad de } \\
\text { Guayaquil. Ex Diputado de la } \\
\text { Izquierda Democrática. }\end{array}$ \\
\hline \multirow{2}{*}{$\begin{array}{l}\text { Ministerio de Economía } \\
\text { y Finanzas }\end{array}$} & \multirow[b]{2}{*}{2} & Ricardo Patiño & $\begin{array}{l}15 / 01 / 07- \\
25 / 07 / 07\end{array}$ & Economista. 54 años. \\
\hline & & Fausto Ortiz & $\begin{array}{l}25 / 07 / 07- \\
\text { actualidad }\end{array}$ & $\begin{array}{l}\text { Economista, Universidad Católica de } \\
\text { Guayaquil; Masterado en Economía } \\
\text { empresarial, INCAE, Costa Rica. }\end{array}$ \\
\hline
\end{tabular}

Ministerio de Agricultura, Ganadería, Acuicultura y Pesca (ex Ministerio de Agricultura 1 Carlos Vallejo 15/01/07- Ingeniero Agrónomo, Universidad y Ganadería modificado actualidad Central del Ecuador. 15/01/07)

\begin{tabular}{|c|c|c|c|c|}
\hline \multirow{3}{*}{$\begin{array}{l}\text { Ministerio de Transporte y } \\
\text { Obras Públicas (sustituye al ex } \\
\text { Ministerio de Obras Públicas } \\
\text { y Comunicaciones (creado } \\
\text { 15/01/07) }\end{array}$} & \multirow{3}{*}{3} & TrajanoAndrade & $\begin{array}{l}15 / 01 / 07- \\
15 / 06 / 07\end{array}$ & $\begin{array}{l}\text { Ex Funcionario de la Izquierda } \\
\text { Democrática. }\end{array}$ \\
\hline & & Héctor Villagrán & $\begin{array}{l}09 / 07 / 07- \\
01 / 12 / 07\end{array}$ & \\
\hline & & Jorge Marún & $\begin{array}{l}\text { 01/12/07- } \\
\text { actualidad }\end{array}$ & Ingeniero civil \\
\hline
\end{tabular}


Continuación Tabla 4

\begin{tabular}{|c|c|c|c|c|}
\hline Ministerio & Cambios & Ministros & Período & Datos biográficos \\
\hline \multirow{2}{*}{$\begin{array}{l}\text { Ministerio de Gobierno, Cultos, } \\
\text { Policía y Municipalidades }\end{array}$} & \multirow{2}{*}{2} & Gustavo Larrea & $\begin{array}{l}15 / 01 / 07- \\
29 / 11 / 07\end{array}$ & $\begin{array}{l}\text { Sociólogo, Universidad Católica } \\
\text { Andrés Bello en Caracas y } \\
\text { Universidad Central del Ecuador. } \\
\text { Ex Subsecretario en el Gobierno del } \\
\text { Partido Roldosista Ecuatoriano. } 50 \\
\text { años. }\end{array}$ \\
\hline & & $\begin{array}{l}\text { Fernando } \\
\text { Bustamante (e) }\end{array}$ & $\begin{array}{l}\text { 29/11/07- } \\
\text { actualidad }\end{array}$ & $\begin{array}{l}\text { Sociólogo, Universidad Católica de } \\
\text { Chile; Masterado en Planificación } \\
\text { Regional y Urbana, Universidad } \\
\text { Católica de Chile (CIDU); Masterado } \\
\text { en Administración Pública, } \\
\text { Universidad de Harvard. } 58 \text { años. }\end{array}$ \\
\hline
\end{tabular}

Ministerio de Relaciones

Exteriores, Comercio e

Integración (ex Ministerio

de Relaciones Exteriores.

modificado 15/01/07)
María Fernanda $\quad$ 15/01/07-

Espinosa $\quad 07 / 12 / 07$

2

María Isabel

Salvador

07/12/07- Universidad Católica del Ecuador;

actualidad Estudios de lengua francesa,

Universidad de Ginebra, Suiza.

\begin{tabular}{|c|c|c|c|c|}
\hline $\begin{array}{l}\text { Ministerio de Cultura (Creado } \\
15 / 01 / 07 \text { ) }\end{array}$ & 1 & Antonio Preciado & $\begin{array}{l}15 / 01 / 07- \\
\text { actualidad }\end{array}$ & $\begin{array}{l}\text { Licenciatura en Política y Economía. } \\
\text { Reconocido poeta. } 56 \text { años. }\end{array}$ \\
\hline \multirow[b]{2}{*}{$\begin{array}{l}\text { Ministerio de Coordinación } \\
\text { de la Producción (Creado } \\
\text { 15/02/07) }\end{array}$} & \multirow[b]{2}{*}{2} & $\begin{array}{l}\text { Mauricio } \\
\text { Dávalos }\end{array}$ & $\begin{array}{l}16 / 02 / 07- \\
01 / 12 / 07\end{array}$ & \\
\hline & & $\begin{array}{l}\text { Susana Cabeza } \\
\text { de Vaca }\end{array}$ & $\begin{array}{l}01 / 12 / 07- \\
\text { actualidad }\end{array}$ & $\begin{array}{l}\text { Estudios superiores, Kalamazoo } \\
\text { College, Estados Unidos, fue } \\
\text { candidata a PhD, Universidad Estatal } \\
\text { de Michigan. }\end{array}$ \\
\hline $\begin{array}{l}\text { Ministerio de Coordinación } \\
\text { de Desarrollo Social (Creado } \\
\text { 15/02/07) }\end{array}$ & 1 & Nathalie Cely & $\begin{array}{l}\text { 06/03/07- } \\
\text { actualidad }\end{array}$ & $\begin{array}{l}\text { Economista, Universidad Católica } \\
\text { de Guayaquil. Masterado en } \\
\text { Administración Pública y Diplomado } \\
\text { en Políticas Públicas y Sociales, } \\
\text { Universidad de Harvard. Candidata } \\
\text { a Doctora en Economía del } \\
\text { Desarrollo, FLACSO. }\end{array}$ \\
\hline
\end{tabular}

\begin{tabular}{llll}
\hline & Ricardo Patiño & $\begin{array}{r}25 / 07 / 07- \\
09 / 12 / 07\end{array}$ \\
\cline { 2 - 4 } $\begin{array}{l}\text { Ministerio del Litoral (Creado } \\
\text { el 25/07/07) }\end{array}$ & 2 & $\begin{array}{l}\text { Economista, Universidad de } \\
\text { Carolina } \\
\text { Portalupi (e) }\end{array}$ & $\begin{array}{l}\text { Guayaquil; diplomados en } \\
\text { actualidad }\end{array}$ \\
& & $\begin{array}{l}\text { Investigación Social y en Nuevos } \\
\text { Paradigmas de la Educación } \\
\text { Superior, Universidad Casa Grande. }\end{array}$ \\
\hline
\end{tabular}

Continúa en página siguiente 
Continuación Tabla 4

\begin{tabular}{|c|c|c|c|c|}
\hline Ministerio & Cambios & Ministros & Período & Datos biográficos \\
\hline $\begin{array}{l}\text { Ministerio de Justicia y } \\
\text { Derechos Humanos* } \\
\text { (creado el 15/11/ 07) }\end{array}$ & 1 & Gustavo Jalkh & $\begin{array}{l}\text { 15/11/ 07- } \\
\text { actualidad }\end{array}$ & Doctor en Derecho \\
\hline Ministerio de Salud Pública & 1 & Caroline Chang & $\begin{array}{l}15 / 01 / 07- \\
\text { actualidad }\end{array}$ & $\begin{array}{l}\text { Doctora en Medicina y Cirugía, } \\
\text { Universidad Católica Santiago de } \\
\text { Guayaquil; egresada de Maestría en } \\
\text { Gerencia en Salud para el Desarrollo } \\
\text { Local. }\end{array}$ \\
\hline \multirow{2}{*}{ Ministerio de Turismo } & \multirow{2}{*}{2} & $\begin{array}{l}\text { María Isabel } \\
\text { Salvador }\end{array}$ & $\begin{array}{l}15 / 01 / 07- \\
07 / 12 / 07\end{array}$ & $\begin{array}{l}\text { Ver Ministerio de Relaciones } \\
\text { Exteriores }\end{array}$ \\
\hline & & Carlos Proaño (e) & $\begin{array}{l}\text { 07/12/07- } \\
\text { actualidad }\end{array}$ & M \\
\hline
\end{tabular}

Ministerio de Industrias

y Competitividad

(ex Ministerio de Comercio

Exterior, Industrialización,

Pesca y Competitividad

modificado 15/01/07)
Economista, Universidad Central de Ecuador; postgrados en Administración para el Desarrollo,

\section{Raúl Sagasti}

15/01/07- Fundación Gertrudio Vargas, Brasil; actualidad Planificación Urbana y Regional, Universidad Central del Ecuador; Economía de la Energía, Bariloche, Argentina.

Ministerio de Inclusión Económica y Social (ex Ministerio de Bienestar Social, modificado 23/08/07)

\begin{tabular}{|c|c|c|c|c|}
\hline Ministerio de Educación & 1 & Raúl Vallejo & $\begin{array}{l}\text { 15/01/07- } \\
\text { actualidad }\end{array}$ & $\begin{array}{l}\text { Licenciado en Literatura, } \\
\text { Universidad Católica de } \\
\text { Guayaquil; Masterado en artes } \\
\text { y literatura latinoamericana, } \\
\text { Universidad de Maryland. } \\
\text { Ex ministro de la Izquierda } \\
\text { Democrática. }\end{array}$ \\
\hline $\begin{array}{l}\text { Ministerio de Desarrollo } \\
\text { Urbano y Vivienda }\end{array}$ & 1 & $\begin{array}{l}\text { María de los } \\
\text { Ángeles Duarte }\end{array}$ & $\begin{array}{l}\text { 15/01/07- } \\
\text { actualidad }\end{array}$ & $\begin{array}{l}\text { Arquitecta, Universidad Católica } \\
\text { Santiago de Guayaquil; Masterado } \\
\text { en Administración de Empresas } \\
\text { Constructoras e Inmobiliarias, } \\
\text { con el aval de la Universidad } \\
\text { Politécnica de Madrid. } 45 \text { años. }\end{array}$ \\
\hline
\end{tabular}


Continuación Tabla 4

\begin{tabular}{|c|c|c|c|c|}
\hline Ministerio & Cambios & Ministros & Período & Datos biográficos \\
\hline \multirow{4}{*}{ Ministerio de Defensa Nacional } & \multirow{4}{*}{4} & $\begin{array}{l}\text { Guadalupe } \\
\text { Larriva + }\end{array}$ & $\begin{array}{l}15 / 01 / 07- \\
24 / 01 / 07\end{array}$ & $\begin{array}{l}\text { Doctora en Geografía e Historia. } \\
\text { Ex Diputada del Partido Socialista. }\end{array}$ \\
\hline & & Ricardo Patiño (e) & $\begin{array}{l}26 / 01 / 07- \\
02 / 02 / 07\end{array}$ & \\
\hline & & Lorena Escudero & $\begin{array}{l}02 / 02 / 07- \\
31 / 08 / 07\end{array}$ & \\
\hline & & $\begin{array}{l}\text { Wellington } \\
\text { Sandoval }\end{array}$ & $\begin{array}{l}\text { 31/08/07- } \\
\text { actualidad }\end{array}$ & $\begin{array}{l}\text { Doctor en Medicina y Cirugía por } \\
\text { la Universidad Central del Ecuador, } \\
\text { Internado, hospital Mount Vernon, } \\
\text { en Nueva York, en Estados Unidos. } \\
\text { Postgrado el Hospital Henry } \\
\text { Ford; Estudios de especialización, } \\
\text { Universidad de Toronto, en Canadá. }\end{array}$ \\
\hline $\begin{array}{l}\text { Ministerio del Deporte } \\
\text { (Creado 15/01/ 07) }\end{array}$ & 1 & Raúl Carrión & $\begin{array}{l}15 / 01 / 07 \\
\text { actualidad }\end{array}$ & $\begin{array}{l}\text { Médico, Universidad Católica de } \\
\text { Guayaquil; postgrado, Universidad } \\
\text { Católica de Río de Janeiro y en } \\
\text { el Hospital Pedro Ernesto de la } \\
\text { Universidad del Estado de Río de } \\
\text { Janeiro. } 48 \text { años. }\end{array}$ \\
\hline
\end{tabular}

\begin{tabular}{|c|c|c|c|c|}
\hline $\begin{array}{l}\text { Ministerio de Coordinación de } \\
\text { Seguridad Interna y Externa } \\
\text { (Creado 15/02/07) }\end{array}$ & 1 & $\begin{array}{l}\text { Fernando } \\
\text { Bustamante }\end{array}$ & $\begin{array}{l}16 / 02 / 07- \\
\text { actualidad }\end{array}$ & \\
\hline \multirow{2}{*}{$\begin{array}{l}\text { Ministerio de Coordinación de } \\
\text { Patrimonio Cultural y Natural } \\
\text { (Creado 15/02/07) }\end{array}$} & \multirow{2}{*}{2} & Juan Martínez & $\begin{array}{l}08 / 05 / 07- \\
15 / 11 / 07\end{array}$ & \\
\hline & & Doris Solís & $\begin{array}{l}\text { 15/11/07- } \\
\text { actualidad }\end{array}$ & Socióloga \\
\hline \multirow{2}{*}{$\begin{array}{l}\text { Ministerio de Coordinación de } \\
\text { Política Económica } \\
\text { (Creado 15/02/07) }\end{array}$} & \multirow{2}{*}{2} & $\begin{array}{l}\text { Mauricio } \\
\text { Dávalos (e) }\end{array}$ & $\begin{array}{l}16 / 02 / 07- \\
31 / 10 / 07\end{array}$ & \\
\hline & & Pedro Páez & $\begin{array}{l}31 / 10 / 07- \\
\text { actualidad }\end{array}$ & \\
\hline \multirow{3}{*}{$\begin{array}{l}\text { Ministerio de Coordinación } \\
\text { Política } \\
\text { (Creado 15/02/07) }\end{array}$} & \multirow[b]{3}{*}{2} & $\begin{array}{l}\text { Fernando } \\
\text { Bustamante (e) }\end{array}$ & $\begin{array}{l}16 / 02 / 07- \\
09 / 12 / 07\end{array}$ & \\
\hline & & & & Economista, Universidad Autónoma \\
\hline & & Ricardo Patiño & $\begin{array}{l}09 / 12 / 07- \\
\text { actualidad }\end{array}$ & $\begin{array}{l}\text { Metropolitana, México, D.F; Post- } \\
\text { grado, en Desarrollo Económico, } \\
\text { Universidad Internacional de } \\
\text { Andalucía, España. } 54 \text { años. }\end{array}$ \\
\hline
\end{tabular}

Total cambios 43

Fuente: Elaboración del autor con datos de la página Web de la Presidencia de la República. 
piso a la oposición. Entre los diputados destituidos constaban 24 del PRIAN, 22 del PSP, 10 del PSC y 1 de la UDC. El 20 de marzo se principalizan, contrariando las órdenes de sus respectivos partidos, 21 diputados suplentes que se alinean con el gobierno y le dan quórum al Congreso para sesionar. Esta estrategia del gobierno invierte los papeles y coloca en situación mayoritaria a minoría de izquierda que cuenta con el respaldo de los 21 legisladores que conformarían el denominado bloque de la "Dignidad Nacional". El 23 de marzo la otrora mayoría principaliza 14 diputados suplentes pero ni ello, ni las principalizaciones posteriores, volvería a invertir la situación. Sin embargo, el apoyo al gobierno por parte del bloque de la "Dignidad Nacional" empieza a desmoronarse a mediados de año. La respuesta del gobierno, es la promesa de gobernar sin el Parlamento y la sugerencia de que el Congreso debería ser cerrado por la Asamblea Constituyente (Hoy on line, 2007w). En adelante, y ya en una fervorosa campaña electoral, la confrontación política cede espacio a la confrontación electoral hasta que un ya muy golpeado y debilitado Congreso es declarado en receso indefinido por la Asamblea el 29 de noviembre. Este debilitamiento se reflejaría también en la capacidad de los partidos para retener a los legisladores en sus filas. La Tabla 5 muestra la composición del Congreso en tres fechas claves y sus correspondientes cambios en la correlación de fuerzas.

Tabla 5: Composición partidaria del Congreso

\begin{tabular}{lccc}
\hline \multicolumn{1}{c}{ Partido } & 5 de enero 2007 & 23 marzo 2007 & 31 diciembre 2007 \\
\hline PRIAN & 28 & 11 & 5 \\
PSP & 24 & 5 & 5 \\
PSC & 13 & 6 & 3 \\
ID & 7 & 7 & 8 \\
PRE & 6 & 6 & 6 \\
MPD & 3 & 3 & 3 \\
MUPP-NP & 6 & 6 & 6 \\
UDC & 5 & 5 & 4 \\
PSFA & 1 & 1 & 1 \\
RED & 5 & 5 & 5 \\
MCNP & 1 & 1 & 1 \\
ARE & 1 & 1 & 1 \\
Dignidad Nacional & - & 21 & - \\
Sin afiliación & - & - & 51 \\
TOTAL & 100 & 78 & 99 \\
\hline
\end{tabular}

Fuentes: Para la composición del Congreso al 5 de enero (Machado, 2007); al 23 de marzo (El Universo, 2007c); al 31 de enero (Congreso Nacional de la República del Ecuador).

El irrespeto a las minorías políticas y las leyes fue nuevamente una constante en la estructuración interna del Congreso. Ello pese a la existencia de disposiciones que establecen el principio de proporcionalidad y regulan claramente el funcionamiento del 
Congreso (Art. 126 y ss. Constitución y Reglamento Interno de la Función Legislativa). La conformación de las dieciocho comisiones especializadas, conformada por siete vocales cada una y a través de las cuales funciona el Congreso de manera ordinaria y permanente, no reflejó el peso de los distintos partidos en el Congreso sino la voluntad de la mayoría de turno. A inicios de año la mayoría anticonstituyente captó la presidencia de la totalidad de las comisiones (7 PRIAN; 6 PSP; 4 PSC y 1 UDC) (Congreso Nacional, 2007a). La revancha fue dulce para los partidos de izquierda. A la destitución de los diputados en marzo siguió la reestructuración total de las comisiones. En esa ocasión las presidencias se repartieron exclusivamente entre la nueva mayoría (3 RED; 3 ID; 3 MUPP; 3 Dignidad Nacional; 2 PRE; 1 MPD; 1 PS-FA; 1 NP; 1 ARE). Adicionalmente, el PRIAN, PSP y PSC tan sólo retuvieron 22 de las 126 vocalías (Explored, 2007e).

\section{RELACIÓN ENTRE LOS PODERES DEL ESTADO}

Pese al principio de la independencia de poderes consagrado en la Constitución, las relaciones entre los poderes del Estado se han caracterizado tradicionalmente por el constante conflicto entre el Ejecutivo y el Legislativo y la politización del Poder Judicial (Mejía, 2008). A partir de 1997, el régimen ecuatoriano ha experimentado transformaciones que en la práctica lo han alejado del presidencialismo puro para aproximarlo a un sistema de tipo híbrido que mezcla el Ejecutivo unipersonal propio de presidencialismo con la posibilidad de revocatoria de mandato propia del parlamentarismo (Lijphart, 1999). Es así que desde la fecha mencionada ningún presidente popularmente electo ha logrado terminar su mandato constitucional y ha sido cesado en el cargo por resolución legislativa (Polga-Hecimovich, 2006). Lo atípico del 2007 no es por lo tanto la intromisión y remoción de un poder por el otro, sino la profundización de este rasgo, el hecho de que se trate de la primera vez en que el Ejecutivo pase de poder anulado a poder anulador (actuando indirectamente sea a través del TSE o de la AC), y de que a esta remoción haya seguido la asunción de las facultades del poder anulado por el poder anulador en lugar de la inmediata restitución del primero (ver sección I.4). En este contexto de concentración de poder hechos que serían relevantes en otras circunstancias, tales como el enjuiciamiento político y posterior censura del ministro de Economía y de la ministra de Ambiente Ana Albán, o la derogatoria legislativa de los decretos de emergencia emitidos por el presidente, carecen prácticamente de relevancia (Hoy on line, 2007x).

La crónica situación de vulnerabilidad de la función judicial en el Ecuador continúa siendo un problema mayor. Nuevamente la existencia de la Corte Suprema de Justicia (CSJ), nombrada en el 2005 en lo que quizá sea el proceso de conformación de este organismo más transparente del período democrático, pendió de la decisión de cinco de los nueve magistrados del altamente politizado TC sobre un recurso de amparo. Ello ocurrió en un contexto de pugna entre estos dos tribunales cuando la CSJ se negó a acatar una resolución del TC (Hoy on line, 2007y). La intromisión de poderes entre los poderes del Estado fue evidente también en la resolución de destitución del TSE en contra de Juez 15 de lo penal del Guayas, Juan José Ramírez, por haber aceptado el recurso de amparo interpuesto por los legisladores destituidos (ver sección I.4). 


\section{RELACIÓN ENTRE LOS DISTINTOS NIVELES DE GOBIERNO}

La batalla entre el gobierno y la partidocracia se extendió también a nivel local en una estrategia orientada a disputar los últimos espacios de poder conservados por los partidos políticos. Anivel provincial, el gobierno muy hábilmente impulsó la creación de dos nuevas provincias, la Provincia de Santa Elena y la Provincia de Santo Domingo de los Tsáchilas, escisiones territoriales de la Provincia de Guayas y Pichincha, respectivamente. En un país en donde los apoyos electorales están fuertemente anclados a nivel provincial y se habla incluso de bastiones electorales a dicho nivel (Freidenberg y Alcántara, 2001) esto significó asestar un duro golpe a partidos que han controlado tradicionalmente dichos espacios: la ID y la UDC en Pichincha y el PSC, PRIAN, PRE en la provincia del Guayas. Más todavía cuando se trata de las provincias con mayor magnitud electoral con $14 \mathrm{y}$ 18 representantes al Congreso Nacional, respectivamente. Por otra parte, el gobierno cuestionó duramente la transparencia de los poderosos gobiernos municipales de Quito (capital de la Provincia de Pichincha y controlado por la ID) y de Guayaquil (capital de la Provincia del Guayas y controlado por el PSC) (Revista Vistazo, 2007bc; Hoy on line, $2007 z$,). Este último trató de construir cierta oposición, pero fue reiteradamente vencido por el gobierno. Un último golpe vendría con la aprobación de la reforma tributaria por la $\mathrm{AC}$ a finales de año que debilita a las finanzas municipales al eliminar la posibilidad de que el impuesto a la renta de los contribuyentes pueda ser donado a las municipalidades. Esta ley también elimina las fundaciones, lo que afecta particularmente al PSC en Guayaquil que ha utilizado esta figura jurídica para manejar fondos públicos relacionados con la gestión municipal (El Universo, 2007d).

La Provincia de Orellana fue nuevamente escenario de tensiones con el gobierno central. Un paro en la parroquia de Dayuma a finales de noviembre, que se inició como protesta por la paralización de la construcción de una carretera, se transformó en acciones de vandalismo que paralizaron la producción petrolera, dieron lugar a la declaratoria de estado de emergencia y a la brutal arremetida de la fuerza pública. La prensa reportó 25 personas detenidas con cargos de terrorismo y sabotaje (Presidencia de la República, 2007c). Días después la Prefecta de Orellana fue detenida acusada de promover los desmanes (El Universo, 2007e). Destaca también la aprobación por el Congreso de la reforma a la Ley 010 propuesta por el Ejecutivo por la cual se eleva de $\Varangle 50$ a \$1 el monto que recibirán las provincias amazónicas por cada barril de crudo producido. No obstante, esta ley ha sido acusada de divisoria en la medida que elimina la distribución igualitaria de los recursos para dar paso a una proporcional basada en la producción (Hoy on line, 2007za).

\section{EVALUACIÓN GENERAL SOBRE EL FUNCIONAMIENTO Y CALIDAD DE LA DEMOCRACIA}

El 2007 fue un año de un marcado deterioro de la democracia y de demolición de la escasa institucionalidad existente. Desde su mismo inicio, el proceso de convocatoria a la AC evidenció una acentuación de las debilidades crónicas de la democracia ecuatoriana tales 
como la pugna de poderes, el mezquino accionar de una clase política absolutamente desconectada de la sociedad y dedicada a defender sus prebendas y espacios de poder, y el secuestro de los órganos de control horizontal por parte de los partidos políticos. Ello dio lugar a una larga cadena de ilegalidades que resultó en la recurrente violación a normas constitucionales, la utilización de agencias de control estatales para amenazar y atentar contra los propios poderes del Estado y el cambio en la conformación de agencias de control claves (como el TC y el TSE) en virtud de la coyuntura política. Todo esto en un contexto de creciente desprestigio de los partidos políticos, alentados tanto por su torpe accionar al recurrir en tal contexto nuevamente a las prácticas ilegales y corruptas que les valieron el repudio de la ciudadanía, y a la presencia del fuerte y exitoso liderazgo antisistema del presidente Correa. ${ }^{6}$

El control absoluto de la AC de plenos poderes por parte de la agrupación política del presidente Correa siembra serias dudas sobre el futuro de la democracia. Ello es inquietante por cinco factores adicionales. Primero, la desaparición del sistema de partidos y de la tradicional fragmentación ecuatoriana anula cualquier posibilidad de contrapesos o de oposición en la arena formal. Segundo, la cooptación de las agrupaciones políticas de izquierda y fundamentalmente del poderoso movimiento indígena anula prácticamente también la oposición en la arena social. Tercero, el tradicionalmente muy débil estado de derecho existente es virtualmente anulado por el control político de las agencias de control horizontal por parte de una agrupación política en solitario. Cuarto, el liderazgo excesivamente personalista del presidente Correa que parece incluso supeditar a la propia AC a su voluntad personal. Quinto, el accionar poco democrático y excluyente exhibido por la AC desde su instalación en el que destaca el desconocimiento del estatuto de funcionamiento que la originó, un fuerte proceso de concentración de poder y la limitada inclinación al diálogo.

\section{REFERENCIAS}

Agencia de Noticias de la Policía del Ecuador. 2007. Síntesis Informativa-Política. 25 abril. [En línea] <http://www.policiales.coberturadigital.com/2007/04/25/sintesis-informativa-politica-58/> [Consulta: 16-03-2008].

Banco Central del Ecuador. Sitio Web. [En línea] http:/ / www.bce.fin.ec/. [Consulta: 15-01-2008].

Banco Central del Ecuador. 2007a. Ecuador: Evolución de la balanza Comercial. Enero-diciembre de 2006, Dirección General de Estudios.

BBC Mundo.com. 2007. Ecuador se retira de maniobras navales. 3 de mayo. [En línea] <http://news.bbc. co.uk/hi/spanish/latin_america/newsid_6619000/6619199.stm> [Consulta: 16-01-2008].

6 Con respecto al primer punto vale la pena destacar la controversial designación de Francisco Cucalón Rendón, esta vez cuota del PSP, al cargo de ministro Fiscal de la Nación. Lo controversial de la designación no provino solamente de las irregularidades en su designación, sino porque Cucalón había ya enfrentado cargos de corrupción que lo obligaron a renunciar cuando fue Fiscal General durante la administración de Bucaram en 1997. En esta ocasión, la ola de protestas que desató su designación lo forzaron a presentar su renuncia a tan solo 13 días de su posesión (Mejía, 2008). 
Cedatos/Gallup International. 2007. Presidente cumplió su primer año de Gobierno con el 57\% de Aprobación a su gestión y Credibilidad del 48\%. 15 de enero. [En línea] <http:/ / www.cedatos.com. ec/contenido.asp?id=42> [Consulta: 16-01-2008].

Centro Carter. 2007. Comunicado de prensa $\mathrm{N}^{\circ} 3$, Centro Carter acompaña la consolidación democrática en el Ecuador. 1 de octubre. En línea] <http://www.cartercenter.org/news/pr/ecuador_100107. html> [Consulta: 03-01-2008].

CLACSO. 2007. "Ecuador: Cronología del conflicto social" [En línea] <www.clacso.org.ar/difusion/ secciones/osal/Descargables/ecuador/ecuador.pdf $>$ [Consulta: 10-01-2008].

CONAMU (Consejo Nacional de las Mujeres). 2007. TSE reglamento Alternabilidad y Secuencia. Boletín mayo. [En línea] http://organizaciones.conamu.gov.ec:8080/informativo/index.php?option=com_c ontent\&task=view\&id=79\&Itemid=13. [Consulta: $15-01-2008]$.

Congreso Nacional de la República del Ecuador. Sitio Web. [En línea] <http://www.congreso.gov.ec> [Consulta: 15-01-2008].

Congreso Nacional. 2007a. Congreso integró comisiones especializadas. Noticias. 13 de enero. [En línea] <http://www.eluniverso.com/2007/03/23/0001/8/46AEB4F2358341C1ADC163186F85E605.aspx> [Consulta: 15-01-2008].

CRE Satelital. 2007. Decreto presidencial suprime la UDENOR. 6 de noviembre. [En línea] <http:/ / www. cre.com.ec $/$ Desktop.aspx?Id=143\&e=103344 $>$ [Consulta: 15-01-2008].

Cueva Simón. 2007. El ministro más veloz. Análisis diario Hoy. 3 de enero. [En línea]. <http:/ / www.hoy. com.ec $/$ NotiDinero.asp?row_id $==255193>$ [Consulta: 15-01-2008].

DW-World.De. 2008. Precio del petróleo alcanza por primera vez récord de 100 dólares. 2 de enero. [En línea] <http:/ / www.dw-world.de/dw/article/0,2144,3035004,00.html> [Consulta: 015-01-2008].

Ecuadorinmediato. 2007a. Chávez cree que Ecuador ingresará al ALBA más pronto que tarde. 29 de abril. [En línea] <http:/ / www.ecuadorinmediato.com/noticias/53161> [Consulta: 15-01-2008].

Ecuadorinmediato. 2007b. Ecuador y China: En busca del Oriente perdido. 24 de noviembre. [En línea] $<$ http://www.ecuadorinmediato.com/noticias/65629> [Consulta: 16-01-2008].

El Diario.com.ec. 2007. Deterioro en la balanza comercial. 30 de octubre. [En línea] <http:/ / www.eldiario. com.ec/noticias-manabi-ecuador/57936> [Consulta: 03-01-2008].

El Mercurio. 2007. Eduardo Somensatto declarado no grato. 27 de abril. [En línea] <http://www. elmercurio.com.ec/web/titulares.php?nuevo_mes=04\&nuevo_ano=2007\&dias=27\&seccion=LPd YzLB > [Consulta: 16-01-2008].

El País.com. 2007. El presidente Correa firma el regreso de Ecuador a la OPEP tras 15 años. 18 de noviembre. [En línea] <http:/ /www.elpais.com/articulo/economia/presidente/Correa/firma/regreso/Ecuador/ OPEP/anos/elpepueco/20071118elpepueco_2/Tes> [Consulta: 16-01-2008].

El Tiempo.com.ec. 2007. Ecuador marca distancia de Venezuela y se proyecta a toda la región. 20 de mayo. [En línea] <http://www.eltiempo.com/internacional/latinoamerica/chavismoenlatinoamerica/ ARTICULO-WEB-NOTA_INTERIOR-3563309.html> [Consulta: 15-01-2008].

El Universo. 2007a. Ministerio de Defensa refuerza control en frontera con Colombia. 25 de noviembre. [En línea] <http:/ / www.eluniverso.com/2007/11/25/0001/8/3823F9A3106C4B2283D78DD53631 7DCB.aspx> [Consulta: 15-01-2008].

El Universo. 2007b. Está lista mayoría anticonstituyente. 2 de enero. [En línea] <http:/ / www.eluniverso.c om/2007/01/02/0001/8/67FAC1FD9650492DA6A0DC98CE9FF3D0.aspx> [Consulta: 03-01-2008].

El Universo. 2007c. Ex mayoría busca 'partir' al bloque de diputados suplentes. 23 de marzo. [En línea] <http://www.eluniverso.com/2007/03/23/0001/8/46AEB4F2358341C1ADC163186F85E605.aspx> [Consulta: 16-01-2008].

El Universo. 2007d. Correa va contra las fundaciones. 9 de diciembre. [En línea] <http:/ /www. eluniverso.com/2007/12/09/0001/18/D8A7D3F5D9D04E17824A2210C2DFD17F.aspx> [Consulta: 16-01-2008].

El Universo. 2007e. Detenida la prefecta Llori por terrorismo. 9 de diciembre. [En línea] <http:/ /www. eluniverso.com/2007/12/09/0001/9/A38A9AAAE5954CF397FA2D0D39F6B621.aspx> [Consulta: 16-01-2008].

Explored. 2007a. Convenios firmados entre Venezuela y Ecuador. 17 de enero. [En línea] <http://www. explored.com.ec/infodat/textofinal.asp?numero=256391\&texto=venezuela> [Consulta: 15-01-2008]. 
Explored. 2007b. Tratado Energético es la meta de la Unasur. 18 de abril. [En línea] <http:/ / www.explored. com.ec/infodat/textofinal.asp?numero=264598\&texto=unasur $>$ [Consulta: 15-01-2008].

Explored. 2007c. Colombia vuelve a fumigar. 7 de febrero. [En línea] <http://www.explored.com.ec/ infodat $/$ textofinal.asp?numero $=258295 \&$ texto $=$ fumigaciones $>$ [Consulta: $15-01-2008]$.

Explored. 2007d. Correa busca el apoyo de los militares. 2 de diciembre [En línea] <http:/ / www.explored. com.ec/infodat $/$ textofinal.asp?numero $=283750 \&$ texto $=$ almacenamiento $\% 20 \mathrm{de} \%>$ [Consulta: 03-01-2008].

Explored. 2007e. El nuevo Parlamento formó las comisiones. 20 de abril. [En línea] <http://www. explored.com.ec/infodat/textofinal.asp?numero $=264850 \&$ texto $=\% 20$ comisiones $\% 20>$ [Consulta: 15-01-2008].

Flavia Freidenberg y Manuel Alcántara. 2001. “Cuestión Regional y Política en Ecuador: Partidos de vocación nacional y apoyo regional". América Latina Hoy 27 (abril): 123-152 (Salamanca: Ediciones Universidad de Salamanca.

Grupo Faro. 2007. “Cómo va la inversión social: Presupuesto inicial 2007”. Mayo. Publicación semestral de UNICEF (Ecuador). N ${ }^{\circ} 19$.

Hoy on line. 2007a. Los 100 días de Rafael Correa. 24 de abril. [En línea] http:/ /www.hoy.com.ec/temas / temas2007/rafaelcorrea/100diascorrea.htm [Consulta: 15-01-2008].

Hoy on line. 2007b. Régimen exige 99\% de ganancia petrolera. 5 de octubre [En línea] <http:/ / www.hoy. com.ec/NoticiaNue.asp?row_id=278954> [Consulta: 15-01-2008].

Hoy on line. 2007c. Las cifras de 2007. 24 de diciembre. [En línea] <http:/ / www.hoy.com.ec/Noticianue. asp?row_id=285402> [Consulta: 16-01-2008].

Hoy on line. 2007d. Refinería en Jaramijó arrancará en 2008. 10 de agosto. [En línea] <http:/ / www.hoy. com.ec/NoticiaNue.asp?row_id=274485> [Consulta: 15-01-2008].

Hoy on line. 2007e. Un taladro venezolano desembarca en Ecuador. 27 de diciembre. [En línea] <http:/ / www.hoy.com.ec/NotiDinero.asp?row_id=285607> [Consulta: 15-01-2008].

Hoy on line. 2007f. Francisco Suéscum recibiría el beneplácito de Colombia. 18 de septiembre. [En línea] <http:/ / www.hoy.com.ec/NoticiaNue.asp?row_id=277554> [Consulta: 15-01-2008].

Hoy on line. 2007g. El Ecuador, sin fecha para demanda contra Colombia. 13 de abril. [En línea] <http:// www.hoy.com.ec/NoticiaNue.asp?row_id=264178> [Consulta: 16-01-2008].

Hoy on line. 2007h. ATPDEA ya está en manos de G. W. Bush. 29 de junio. [En línea] <http:/ / www.hoy. com.ec/NotiDinero.asp?row_id=270947> [Consulta: 16-01-2008].

Hoy on line. 2007i. Los EEUU esperan prórroga para operar Base de Manta. 14 de mayo. [En línea] <http:// www.hoy.com.ec/NoticiaNue.asp?row_id=266889> [Consulta: 16-01-2008]

Hoy on line. 2007j. Agoniza Tratado de Inversiones. 7 de mayo. [En línea] <http:/ /www.hoy.com.ec/ NotiDinero.asp?row_id=266286> [Consulta: 16-01-2008].

Hoy on line. 2007k. Gobierno desconoce arbitraje del Ciadi. 14 de diciembre. [En línea] <http:/ /www. hoy.com.ec/NoticiaNue.asp?row_id=284701> [Consulta: 16-01-2008].

Hoy on line. 2007l. Ecuador no se presta a TLC suicidas. 23 de septiembre. [En línea] <http:/ / www.hoy. com.ec/NoticiaNue.asp?row_id=277939> [Consulta: 16-01-2008].

Hoy on line. 2007m. Congreso: desalojo de diputados y trifulca. 31 de enero. [En línea] <http://www. hoy.com.ec/NoticiaNue.asp?row_id=257662> [Consulta: 03-01-2008].

Hoy on line. 2007n. Transición de gobierno 2007. El Congreso destituye a dos legisladoras de SP. 9 de enero. [En línea] http:/ / www.hoy.com.ec/NoticiaNue.asp?row_id=255704. [Consulta: 03-01-2008].

Hoy on line. 2007o. El hoy on line. 2007. Decisiones cruciales en manos del Congreso. 5 de febrero. [En línea] <http:/ / www.hoy.com.ec/NoticiaNue.asp?row_id=258078> [Consulta: 03-01-2008].

Hoy on line. 2007p. Sopapo a la oposición, con 21 alternos. 21 de marzo [En línea] <http:/ /www.hoy. com.ec/NoticiaNue.asp?row_id=261954> [Consulta: 03-01-2008]

Hoy on line. 2007q. Constitución en Proceso. Asamblea Nacional asume poderes y cesa al Congreso. 30 de noviembre. [En línea] <http://www.hoy.com.ec/NoticiaNue.asp?row_id=283623)> [Consulta: 03-01-2008].

Hoy on line. 2007r. Constitución en Proceso. El debate de las reformas tributarias es de mero trámite. 29 de diciembre [En línea] <http:/ / www.hoy.com.ec/NoticiaNue.asp?row_id=285740> [Consulta: 03-01-2008]. 
Hoy on line. 2007s. Almacenamiento de gas levanta la polvareda . 15 de enero [En línea] <http://www. hoy.com.ec/Notidinero.asp?row_id=286849> [Consulta: 15-01-2008].

Hoy on line. 2007t. El Gobierno crea 545 partidas y elimina solo una. 29 de junio. [En línea] <http:/ / www. hoy.com.ec/NoticiaNue.asp?row_id=270922> [Consulta: 16-01-2008].

Hoy on line. 2007u. El Consejo Nacional de Modernización está a dos firmas de desaparecer. 7 de febrero. [En línea] <http:/ / www.hoy.com.ec/NoticiaNue.asp?row_id=258281> [Consulta: 16-01-2008].

Hoy on line. 2007v. Emergencias, un estilo de Rafael Correa. 7 de marzo. [En línea] <http:/ /www.hoy. com.ec/NoticiaNue.asp?row_id=260638> [Consulta: 16-01-2008].

Hoy on line. 2007w. Cambiante actitud ante el Congreso. Opinión Diario Hoy. 15 de julio. [En línea] <http://www.hoy.com.ec/NoticiaNue.asp?row_id=272310> [Consulta: 16-01-2008].

Hoy on line. 2007x. Se tumban las emergencias del Régimen. 15 de noviembre. [En línea] <http:/ /www. hoy.com.ec/NoticiaNue.asp?row_id=282387> [Consulta: 16-01-2008].

Hoy on line. 2007y. Estabilidad de la Corte en las manos del TC. 19 de febrero. [En línea] <http:/ /www. hoy.com.ec/NoticiaNue.asp?row_id=259327> [Consulta: 16-01-2008].

Hoy on Line. 2007z. CATEG Y ELEVAL: la emergencia da pie a cadena de irregularidades. Especial Blanco y Negro: Periodismo de investigación. 2 de abril. [En línea] <http:/ / www.hoy.com.ec/suplemen/ blan443/byn.htm> [Consulta: 03-01-2008].

Hoy on line. 2007za. División entre amazónicos tras la reforma a Ley 010. 9 de noviembre. [En línea] $<$ http:/ / www.hoy.com.ec/NoticiaNue.asp?row_id=281929> [Consulta: 16-01-2008].

Hoy on line. 2008a. La confianza empresarial se reduce .7 de enero [En línea] <http:/ /www.hoy.com. ec/NotiDinero.asp?row_id=286255> [Consulta: 015-01-2008].

Hoy on line. 2008b. Urgencia de recuperación petrolera. Opinión Diario Hoy. 16 de enero [En línea] <http:/ / www.hoy.com.ec/NoticiaNue.asp?row_id=286936> [Consulta: 16-01-2008].

Hoy on line. 2008c. Opinión de Diario Hoy: Muy bajo crecimiento económico. 3 de enero [En línea] <http:/ / www.hoy.com.ec/Noticianue.asp?row_id=285992> [Consulta: 15-01-2008].

International Crisis Group . 2007. “Ecuador: ¿Superando la Instabilidad?” Informe sobre América Latina $\mathrm{N}^{\circ} 22.7$ de agosto. [En línea] <http://www.crisisgroup.org/library/documents/latin_america/ spanish_and_portuguese/22_ecuador_overcoming_instability_spanish.pdfhttp://www.hoy.com. ec/Notidinero.asp?row_id=286849> . [Consulta: 15-01-2008].

Ley Orgánica de Elecciones de la República del Ecuador. Constitución Política de la República del Ecuador, 1998.

Lijphart, Arendt. 1999. "Patterns of democracy: government forms and performance in thirty-six countries." New Haven, Yale University Press.

Los Tiempos.com. 2007. Irán y Ecuador estrechan relaciones. 2 de agosto. [En línea] <http://www. lostiempos.com/noticias/02-08-07/02_08_07_ultimas_int5.php> [Consulta: 16-01-2008].

Machado Puertas, Juan Carlos. 2007. "Ecuador: el derrumbe de los partidos tradicionales." Rev. cienc. polit. (Santiago). vol. 27, No esp., p. 129-147 [online]. <http:/ / www.scielo.cl/scielo.php?script=sci_ arttext\&pid=S0718-090X2007000100008\&lng=es\&nrm=iso >. [Consulta: 03-01-2008].

Mejía-Acosta, Andrés. 2008. "Country Report: Ecuador. In Countries at the Crossroads", Freedom House. Editado por Sanja Kelly, Christopher Walker, and Jake Dizard. Rowman and Littlefield. [En línea] $<$ http:/ / www.freedomhouse.org/template..$f m$ ?page=140\&edition=8\&ccrpage=37\&ccrcountry=175> . [Consulta: 03-01-2008].

Mejia-Acosta, Andrés. (2006). “Crafting Legislative Ghost Coalitions in Ecuador Informal Institutions and Economic Reform in an Unlikely Case". En Informal Institutions \& Democracy lessons from Latin America, editado por G. Helmke y S. Levitsky. Baltimore, Maryland, The Johns Hopkins University Press: 69-84.

Ministerio de Relaciones Exteriores del Ecuador. Plan Ecuador. http://www.mmrree.gov.ec/mre/ documentos/pol_internacional/plan_ecuador/indice.htm[ Consulta: 16-01-2008].

Noticias del Sur. 2007. El Gobierno marca sus diferencias con EE.UU. 10 de mayo. [En línea] <http:// www.noticiasdelsur.com/nota.php?nota $=423>$ [Consulta: 16-01-2008].

Pachano, Simón. 2007a. Desesperados. 9 de abril. El Universo [En línea]. <http:/ / www.eluniverso.com/ 2007/04/09/0001/21/43AB1D05361845AA821B59ACC2AD929E.aspx> [Consulta: 15-01-2008]. 
Pachano, Simón. 2007b. Números. 20 de agosto. El Universo [En línea]. <http:/ / www.eluniverso.com/2 007/08/20/0001/21/037E220CBC204D1588D83105D6019138.aspx> [Consulta: 15-01-2008].

Polga-Hecimovich, John. 2006. “La Institución política informal de la destitución presidencial: El Caso Ecuatoriano, 1997-2005". Tesis de Maestría, Universidad Andina Simón Bolívar - Sede Ecuador, 2006.

Presidencia de la República. 2007a.[En línea] <http://www.presidencia.gov.ec/modulos.asp?id=191> [Consulta: 16-01-2008].

Presidencia de la República. 2007b. [En línea] http://www.presidencia.gov.ec/modulos.asp?id=1 [Consulta: 16-01-2008].

Presidencia de la República. 2007c. La Comisión Veedora "Dayuma" presentó informe final con las conclusiones y recomendaciones. 10 de enero. [En línea] <http:/ / www.presidencia.gov.ec/noticias. asp?noid=12278> [Consulta: 16-01-2008].

Presidencia de la República. Sitio web. [En línea] <http:/ / www.presidencia.gov.ec>[Consulta: 15-01-2008].

Reglamento de Funcionamiento de la Asamblea Constituyente. [En línea] http:/ / www.asambleaconstituyente. gov.ec/index.php?option=com_content\&task=view\&id=733\&Itemid=72. [Consulta: 03-01-2008].

Revista Vanguardia. 2007a. "Las seis patas del Estado Correa". [Publicación: 11-12-2007]. Edición 116, 22-24.

Revista Vanguardia. 2007b. "El sistema Correa no perdona". [Publicación: 11-12-2007]. Edición 116, 16-20.

Revista Vistazo. 2007a. "Personajes del año, Rafael Correa: Una aplanadora". [Publicación: 13-12-2007], Edición 968, 46.

Revista Vistazo. 2007b. "Año de esperanza: Titanes en el ring". [Publicación: 13-12-2007], Edición 968, 68. Revista Vistazo. 2007c. "Año de esperanza: Vuelo cruzado". [Publicación: 13-12-2007], Edición 968, 72.

Rivas, José Antonio y Araque José. 2005. "Aventuras y desventuras del populismo en América Latina." En muerte y resurrección del populismo, Metapolítica, noviembre-diciembre, Num 44, 69-77. [En línea]. <http://www.saber.ula.ve/db/ssaber/Edocs/centros_investigacion/cipc/publicaciones/ articulos/aventuras.pdf $>$ [Consulta: 15-01-2008].

RTU. 2007a. Ecuador: Remesas migrantes se incrementaron en 2007. 19 de diciembre. [En línea] <http:/ / www.rtu.com.ec/ver_noticia.php?id_not=3575> [Consulta: 03-01-2008].

RTU. 2007b.Ecuador: TSE prohíbe al gobierno usar fondos públicos en campaña política 23 de agosto. [En línea] <http:/ /www.rtu.com.ec/ver_noticia.php?id_not=3003> [Consulta: 03-01-2008].

Salazar Caldas Estuardo. 2008. Balance 2007 en opinión el Hoy on line. 15 de enero. [En línea]. <http:/ / www.hoy.com.ec/NoticiaNue.asp?row_id=286841> [Consulta: 015-01-2008].

Soitu.es. 2007. Ecuador satisfecho por fallo de la OMC en el tema del banano. 29 de noviembre. [En línea] <http://www.soitu.es/soitu/2007/11/29/info/1196295047_193993.html> [Consulta: 16-01-2008].

Tribunal Supremo Electoral. 2007. Método para la "asignación de escaños", Elección de Representantes a la Asamblea Constituyente. 30 de septiembre. [En línea] http:/ /app.tse.gov.ec/ResultadosAsamblea2007/ Reg_AsigEsc_Asam2007.pdf. [Consulta: 15-01-2008].

Tribunal Supremo Electoral. Sitio Web. [En línea] <http://www.tse.gov.ec/>[Consulta: 15-01-2008].

Juan Carlos Machado Puertas es candidato a PhD en Gobierno en el Instituto de Estudios de Desarrollo (IDS), Universidad de Sussex (j.machado-puertas@ids.ac.uk). 
